OPEN ACCESS

Edited by:

Shintaro Funahashi,

Kyoto University, Japan

Reviewed by:

Shengtao Yang

Yale University, United States

Andreas Nieder,

University of Tübingen, Germany

*Correspondence: Stefan Everling severlin@uwo.ca

Received: 01 January 2021 Accepted: 11 February 2021

Published: 15 March 2021

Citation:

Vijayraghavan S and Everling S (2021) Neuromodulation of Persistent Activity and Working Memory Circuitry in Primate Prefrontal Cortex by

Muscarinic Receptors.

Front. Neural Circuits 15:648624. doi: 10.3389/fncir.2021.648624

\section{Neuromodulation of Persistent Activity and Working Memory Circuitry in Primate Prefrontal Cortex by Muscarinic Receptors}

\author{
Susheel Vijayraghavan ${ }^{1}$ and Stefan Everling ${ }^{1,2 *}$ \\ ${ }^{1}$ Department of Physiology and Pharmacology, The University of Western Ontario, London, ON, Canada, ${ }^{2}$ Robarts \\ Research Institute, The University of Western Ontario, London, ON, Canada
}

Neuromodulation by acetylcholine plays a vital role in shaping the physiology and functions of cerebral cortex. Cholinergic neuromodulation influences brain-state transitions, controls the gating of cortical sensory stimulus responses, and has been shown to influence the generation and maintenance of persistent activity in prefrontal cortex. Here we review our current understanding of the role of muscarinic cholinergic receptors in primate prefrontal cortex during its engagement in the performance of working memory tasks. We summarize the localization of muscarinic receptors in prefrontal cortex, review the effects of muscarinic neuromodulation on arousal, working memory and cognitive control tasks, and describe the effects of muscarinic M1 receptor stimulation and blockade on the generation and maintenance of persistent activity of prefrontal neurons encoding working memory representations. Recent studies describing the pharmacological effects of $\mathrm{M} 1$ receptors on prefrontal persistent activity demonstrate the heterogeneity of muscarinic actions and delineate unexpected modulatory effects discovered in primate prefrontal cortex when compared with studies in rodents. Understanding the underlying mechanisms by which muscarinic receptors regulate prefrontal cognitive control circuitry will inform the search of muscarinic-based therapeutic targets in the treatment of neuropsychiatric disorders.

Keywords: muscarinic acetylcholine receptor, M1 receptor, M2 receptor, working memory, persistent activity, prefrontal cortex, antisaccade, primate

\section{INTRODUCTION}

The ability to maintain and manipulate information about the sensory world, motor actions, and previously learned experience is central to cognition and flexible behavior. Persistent, short-term elevated activity in cortical circuits has been proposed to Fuster and Alexander (1971) and Goldman-Rakic (1995) underlie the capacity to actively maintain such knowledge, or "working memory" (WM). The prefrontal cortex (PFC) in primates plays a pivotal role in the neural circuitry that processes such behaviorally relevant mental representations that are deployed to guide imminent choices and actions (Fuster and Alexander, 1971; Fuster, 1992, 1993; Miller and Cohen, 2001). 
All major ascending neuromodulatory systems innervate the cerebral cortex, including the PFC and influence the dynamics of persistent activity and cortical WM circuitry (Arnsten et al., 2012). The modulatory actions of acetylcholine (ACh) on cortical function have been of long-standing interest partly because cholinergic dysfunction has been implicated in cognitive and WM deficits that manifest in psychiatric and neurological disorders including Alzheimer's disease (Hampel et al., 2018, 2019), dementia associated with Parkinson's disease (Noufi et al., 2019), major depressive disorder (Dagytë et al., 2011), and schizophrenia (Sarter and Bruno, 1998; Dean et al., 2003). Progressive cortical cholinergic deafferentation is a hallmark of Alzheimer's dementia and cholinergic pathology accompanies the cognitive disruption that manifests in the disease (Hampel et al., 2018). Inhibitors of acetylcholinesterase, which breaks down released acetylcholine, is a standard component of the treatment regimen in Alzheimer's dementia, although its efficacy in ameliorating cognitive deficits in patients has been questioned (Marucci et al., 2020). Decreased muscarinic receptor density has been reported in patients with schizophrenia (Dean et al., 2002; for detailed review see Dean et al., 2003). Further, xanomeline, a muscarinic agonist has shown clinical promise and improves short-term memory and other cognitive functions in schizophrenic patients (Shekhar et al., 2008).

Acetylcholine mediates its neuromodulatory influence via the ionotropic nicotinic and metabotropic G-protein coupled muscarinic receptor families (Picciotto et al., 2012). Subtypes from both cholinergic receptor families function in cortical WM circuitry, including in the PFC. There has recently been considerable interest in how $\mathrm{ACh}$, acting through these receptors, influences neurophysiology of primate PFC during the performance of WM tasks (Baxter and Crimins, 2018; Galvin et al., 2018, 2020a; Vijayraghavan et al., 2018). Here, we will review studies of cortical muscarinic neuromodulation of WM performance and recapitulate recent work from our laboratory and others exploring muscarinic neuropharmacology of persistent activity and WM representations in primate PFC. Whereas there are several excellent published synopses regarding the functions of cortical ACh (McCormick, 1993; Steriade, 2004; Picciotto et al., 2012; Venkatesan et al., 2020), nicotinic and muscarinic neuromodulation of cognition and WM (Sarter and Bruno, 1997; Robbins and Arnsten, 2009; Klinkenberg and Blokland, 2010; Wallace and Bertrand, 2013), we will primarily focus on neurophysiological and pharmacological studies in dorsolateral PFC of non-human primates in this review.

\section{LOCALIZATION OF MUSCARINIC RECEPTORS IN PRIMATE PFC}

Among several cholinergic nuclei in the brainstem and basal forebrain, the nucleus basalis of Meynert is the principal source of ACh in the primate cerebral cortex (Mesulam et al., 1983; Lewis, 1991; Smiley et al., 1997). Additionally, in rodents, a fraction of cortical interneurons that express vasoactive intestinal peptide, also coexpress choline acetyltransferase, an enzyme that synthesizes ACh (Eckenstein and Baughman, 1984).
However, hitherto such putatively cholinergic and GABAergic interneurons have not been shown in primate cerebral cortex (Mesulam et al., 1983), and the basal forebrain appears to be the only source of cholinergic innervation of cortex in primates. Corticopetal cholinergic afferents from the nucleus basalis innervate superficial and deep layers of macaque PFC, forming both symmetric synapses and boutons in proximity to symmetric and asymmetric synapses near dendritic spines (Mrzljak et al., 1995). Interestingly, the fraction of cortical cholinergic varicosities exhibiting synaptic specializations increases in primates when compared with rodents and is further augmented in humans (Smiley et al., 1997) versus monkeys (Mrzljak et al., 1995). Thus, ACh innervation of primate PFC has the capacity to act through both synaptic specialization and volume transmission (Mrzljak et al., 1995).

The prominent nicotinic receptor subtypes expressed in macaque cortex, including PFC, are $\alpha 4 \beta 2$ and $\alpha 7$ receptors (Wallace and Bertrand, 2013; Galvin et al., 2018). The muscarinic ACh family is comprised of $\mathrm{G}_{q}$-coupled M1, M3, and M5 receptors and $\mathrm{G}_{i / o^{-}}$-coupled $\mathrm{M} 2$, and $\mathrm{M} 4$ receptor families (Caulfield and Birdsall, 1998; Brown, 2010; Jones et al., 2012). Of these, M1 and M2 receptors are prominently expressed in PFC in primates. M1 receptors (M1Rs) and M2 receptors (M2Rs) are present in PFC in rodents (Levey et al., 1991), primates (Mrzljak et al., 1993; Medalla and Barbas, 2012) and humans (Scarr et al., 2009; Bubser et al., 2011; Dean and Scarr, 2016). M3 receptor expression has been examined in rats and is mainly expressed in the hippocampus and to a lesser extent in cerebral cortex, where it is absent in cortical layer III/IV (Levey et al., 1994; Bubser et al., 2011). However, M3 receptor expression has not been examined thus far in primate cerebral cortex owing to lack of selective immunohistochemical tools in primates. Expression patterns of other muscarinic receptor subtypes in monkey PFC are hitherto unknown.

In rodents, cortical M1 receptors are predominantly expressed postsynaptically (Levey, 1996) and are presumed to mediate the excitatory effect of muscarinic agonists on cortical activity in brain slices (McCormick, 1989, 1993; McCormick et al., 1993). Autoradiography using M1R- and M2R-preferring compounds suggests that M1R laminar expression in monkey PFC is present in all layers with strong bands of expression in layers III and $\mathrm{V}$, while M2Rs are enriched in layer III and V/VI in the PFC, with the exception of Walker's area 46, where the expression is predominantly in layer V (Lidow et al., 1989; Mrzljak et al., 1993).

M1 receptor expression in monkey cortex was examined with immunohistochemistry and mRNA expression in a series of studies by Mrzljak and colleagues (Lidow et al., 1989; Mrzljak et al., 1993, 1996, 1998). In area 46 (dorsolateral PFC) of the macaque, M1Rs were expressed throughout all layers with greatest expression found in supragranular layer III and infragranular layers V/VI. Conspicuous M1R expression was found in the soma, dendrites, dendritic spines, and in close association with both asymmetric (presumably glutamatergic) and symmetric synapses (presumably GABAergic or cholinergic). The presence of M1Rs in conjunction with asymmetric synapses in PFC circuitry points to a role in modulating thalamocortical and corticocortical excitatory transmission. Early 
studies indicated that M2Rs serve as autoreceptors on cholinergic efferents, inhibiting ACh release from terminals (Dudar and Szerb, 1969; Mash et al., 1985; Mash and Potter, 1986), and muscarinic inhibition of the release of tritiated ACh does not occur in M2R knock-out mice (Zhang et al., 2002). Further decline in cortical M2R expression in Alzheimer's disease has been attributed to the degeneration of cholinergic afferents from the basal forebrain (Flynn et al., 1995; Levey, 1996). Remarkably, immunohistochemical examination of the cortical M2Rs in monkey PFC (Mrzljak et al., 1993, 1998) and primary visual cortex (Mrzljak et al., 1996; Disney et al., 2006; Disney and Aoki, 2008) revealed a more complex profile of M2R expression. PFC M2R expression was found in both pre-and postsynaptic specializations, and in both cases, the expression was associated with both symmetric and asymmetric synapses in pyramidal and non-pyramidal neurons (Mrzljak et al., 1993). In primary visual cortex, M2R expression forms interdigitated patches of dense and sparse expression that coincide, respectively, with interblobs and blobs defined by cytochrome oxidase staining (Mrzljak et al., 1996; Disney et al., 2006). M2R expression was more prominent in the parvocellular inferotemporal channel of the visual stream wherein neurons possess orientation tuning but lack color opponency. Thus, M2R expression in primary visual cortex constitutes an intriguing example of convergence between neuromodulatory specialization and functional segregation. Associational and cross-callosal projections also form interdigitated stripes in dorsolateral PFC (Goldman-Rakic and Schwartz, 1982; Schwartz and GoldmanRakic, 1984; Pucak et al., 1996). However, it is hitherto unknown if muscarinic receptor expression demonstrates congruence with these hodological features in PFC. Mrzljak et al. (1993) did not comment on whether anisotropy was observed in the larger scale distribution of M1Rs or M2Rs in their reports on muscarinic receptors in dorsolateral PFC.

However, other elegant work from the Barbas group demonstrated hodological specificity in M2R expression in dorsolateral PFC (Medalla and Barbas, 2012). The cholinergic arousal system remains active during waking and rapid eye movement sleep (REM, "paradoxical sleep"), but not during the slow wave non-REM phase of sleep, in contrast to norepinephrine, the other major neuromodulatory system involved in arousal (Aston-Jones and Bloom, 1981; Lee and Dan, 2012). Additionally, while the cerebral cortex is in a deactivated state during non-REM sleep, positron emission tomography studies have shown that certain limbic prefrontal areas are reactivated earlier upon the transition to REM sleep, while dorsolateral PFC remains deactivated (Muzur et al., 2002). Muzur et al. (2002) proposed that this was due to selective cholinergic inhibition of dorsolateral PFC. Medalla and Barbas (2012) tested this hypothesis in the context of the anterior cingulate cortex (ACC; area 32) and areas 9 and 46 of the dorsolateral PFC. Cholinergic innervation of the ACC is dense in comparison to dorsolateral PFC, and the ACC sends a substantial glutamatergic projection to the latter (Johnston et al., 2007). The ACC is reactivated earlier during REM sleep, and the question remains as to how the dorsolateral PFC does not also get activated concomitantly, given the strong excitatory projection from ACC and restored cholinergic tone in the dorsolateral PFC during REM sleep. Medalla and Barbas (2012) hypothesized that the distribution of M2Rs on ACC projections and their postsynaptic targets could account for the lack of REM sleep activation of dorsolateral PFC. Using serial electron microscopy, fluorescent immunohistochemistry and pathway tracing, Medalla and Barbas (2012) examined M2R expression in area 9 of the PFC. They found that presynaptic M2R expression was enriched in the glutamatergic afferents from ACC to area 9 when compared with associational fibers from PFC area 46. These presynaptic M2Rs, when activated by ACh release in PFC area 9, would lead to presynaptic suppression of glutamate release (Kimura and Baughman, 1997), thus nullifying the strong excitatory drive from the ACC during REM sleep when ACh is being released in the cortical mantle. M2Rs were also found the dendritic shafts of putative inhibitory neurons targeted by the ACC projection, while M2Rs were localized primarily on dendritic spines of pyramidal neurons that were targets of the associational fibers from neighboring PFC area 46. PFC areas 9 and 46 share functional congruence in the generation and maintenance of persistent activity and WM in the cognitive circuitry of dorsolateral PFC, and therefore M2R postsynaptic expression in area 9 pyramidal neurons receiving inputs from area 46 may have facilitatory physiological effects. Similarly, cholinergic suppression in the rat piriform cortex occurs only in synapses associated with intrinsic projections, and not afferent inputs (Hasselmo and Bower, 1992). Thus, M2R expression shows remarkable specificity and correspondence with functional and hodological attributes.

\section{NEUROPHARMACOLOGY OF CORTICAL MUSCARINIC RECEPTORS IN AROUSAL}

The ascending reticular activating system, including the cholinergic and noradrenergic systems, regulate the sleep-arousal cycle and transitions between the different brain states (Moruzzi and Magoun, 1949; Lee and Dan, 2012). During slow-wave sleep (Non-REM sleep), thalamocortical circuitry is in a relatively quiescent slow oscillation with synchronized transitions between silent and active states (Steriade et al., 2001; Constantinople and Bruno, 2011). Signatures of this oscillation are manifest across different physiological scales: the activity of individual neurons and their membrane potential, the local field potential (LFP) and in the scalp electroencephalogram (EEG). Upon transitioning to REM sleep and the wake state, overall activity of individual neurons becomes desynchronized, with concomitant desynchronization in the other electrophysiological signatures of brain states, including the LFP and scalp EEG. The bistable activity seen during slow wave sleep, comprising of brief interludes of quiescence and activity have been termed downand up-states (Contreras and Steriade, 1995). Isolated cortical slices can spontaneously replicate this mode of bistable activity, termed the slow oscillation (Sanchez-Vives and McCormick, 2000). Indeed, this low frequency $(0.1-0.5 \mathrm{~Hz})$ oscillation can be expressed in cultured random cortical networks and deafferented cortical slabs (Sanchez-Vives et al., 2017) and is a unifying feature 
of cortical activity under different anesthetic regimes (Lewis et al., 2012). It has been proposed that this is a default activity pattern and emergent property of cortical networks (Sanchez-Vives et al., 2017). It has also been speculated that the wake state may be akin to a persistent up-state (Constantinople and Bruno, 2011), where oscillatory transitions to quiescence do not occur. In vivo, the dynamics of ascending neuromodulatory arousal systems engender these transitions (Moruzzi and Magoun, 1949; Constantinople and Bruno, 2011; Jones, 2020).

The ascending brainstem and basal forebrain cholinergic systems causally contribute to regulating these physiological transitions accompanying brain state transitions (Metherate et al., 1992; Jones, 2008). A brief discussion of this subject may be useful here, since the physiological mechanisms that are at play in cholinergic modulation of arousal may have commonalities with cholinergic neuromodulation of cortical neurophysiology during cognitive control and WM. Interestingly, as noted previously, cholinergic nuclei are active during REM sleep, when cortical activity, LFP and the EEG are indistinguishable from the wake state, which is not the case for the monoamine arousal systems, which are very active during wakefulness, possess low activity during non-REM sleep, but are completely quiescent during REM sleep. Basal forebrain stimulation in rodents can depolarize auditory cortical neurons, desynchronize their activity with shifts in subthreshold membrane potential oscillations from low $(\leq 5 \mathrm{~Hz})$ to high $(20-40 \mathrm{~Hz})$ oscillations (Metherate et al., 1992). Optogenetic activation of basal forebrain cholinergic neurons, or of terminal projections thereof in the primary visual cortex, desynchronize the LFP and visual cortical neuronal activity. Lee and Dan (2012) proposed that two effects of muscarinic modulation, viz., muscarinic suppression of intracortical synaptic transmission (Gil et al., 1997; Hsieh et al., 2000; Medalla and Barbas, 2012) and muscarinic depolarization of cortical neurons may be instrumental in ACh-induced depolarization during brain state transitions. In mice, ACh neuromodulation of somatostatin-positive interneurons, that participate in a disynaptic disinhibitory relay through their inhibition of parvalbumin positive interneurons, has been shown to be necessary for the desynchronization of neuronal firing and the LFP in somatosensory cortex (Chen et al., 2015). Muscarinic agonists increase REM state duration and decrease the onset latency of REM sleep induction (Sitaram et al., 1976; Hohagen et al., 1993), while muscarinic receptor antagonists decrease the duration of REM sleep (VelazquezMoctezuma et al., 1990; Gillin et al., 1991; Kim and Jeong, 1999). A recent study showed that a double knockout of M1Rs and M3Rs in mice almost completely abolishes REM sleep, indicating that $G_{q}$ coupled muscarinic receptors were essential in regulating this epoch of the sleep rhythm (Niwa et al., 2018).

There are tonic and phasic components to the activity of cholinergic neurons and ACh fluctuations in vivo can be measured by amperometric methods (Parikh et al., 2004, 2007). Amperometric monitoring of $\mathrm{ACh}$ has revealed that tonic $\mathrm{ACh}$ release is coordinated across multiple brain areas during REM sleep, while phasic ACh release is synchronized during performance of a WM task (Ruivo et al., 2017).
To summarize, the cholinergic system is essential in the regulation of states of cortical arousal, and neuromodulation by muscarinic receptors, particularly of the M1R family, are essential in the generation of desynchronized states during REM sleep and awake behavior. Some of the physiological mechanisms that elicit the transitions to wake-like desynchronized cortical activity may also be involved in the neuromodulation of persistent activity in awake cortical circuits engaged in active behavior.

\section{MUSCARINIC MODULATION OF WM AND COGNITIVE CONTROL CIRCUITRY}

A substantial body of work has examined the role of the cholinergic system in cognitive performance in rodents, monkeys, and humans (Fibiger, 1991). Early clues about the importance of muscarinic receptor function in WM performance came from Bartus and Johnson (1976), who found that systemic muscarinic blockade with muscarinic antagonist scopolamine caused a delay-dependent deficit in a match-to-sample WM task, wherein the deficits were pronounced only at longer delays. Thereafter, many studies have replicated and elaborated upon this deficit in WM performance in monkeys (Rusted and Warburton, 1988; Rupniak et al., 1991; Rusted et al., 1991; Spinelli et al., 2006). Interestingly, Rupniak et al. (1991) found that the cholinesterase inhibitor, physostigmine, could reverse pro-amnestic deficits caused by systemic scopolamine, but physostigmine could not improve WM performance in aged monkeys or when distractor load was increased in the task. Moreover, they reported that stimulus luminance did not interact with scopolamineinduced deficits in delayed response performance, whereas increasing attentional load by reducing stimulus presentation time exacerbated scopolamine's effects independent of the length of the delay, leading the authors to argue that systemic muscarinic blockade may affect attentional aspects of task performance, instead of WM. Nevertheless, a gamut of studies have shown that systemic muscarinic blockade caused WM, delayed matchto-sample, recognition memory and other cognitive deficits and pro-psychotic states (Penetar and McDonough, 1983; Aigner et al., 1987; Aigner and Mishkin, 1993; Barak and Weiner, 2006, 2009; Buccafusco et al., 2008; Plakke et al., 2008; Barak, 2009). This has led to the identification of a collection of cognitive deficits and psychosis-like symptoms termed the anti-muscarinic syndrome (Yeomans, 1995). Scopolamine has been shown to affect sensory discrimination, acoustic startle reflex, prepulse inhibition, recognition memory, short-term memory, delayed match-to-sample, set shifting, and attentional performance in rodents (Dunnett et al., 1990; Jones and Shannon, 2000; Ukai et al., 2004; Barak and Weiner, 2006). Systemic muscarinic blockade causes deficits in the WM performance and executive function in humans (Green et al., 2005; Ellis et al., 2006). Muscarinic blockade also produces deficits in the learning of rules specifying outcome-based odor discrimination in rodents (Saar et al., 2001). Lesions of the basal forebrain cholinergic system in monkeys have reported conflicting effects on cognitive tasks. In one study basal forebrain ibotenic acid lesions cause recognition memory and delayed non-match-to-sample performance deficits 
(Aigner et al., 1991). Contrastingly, in another study, lesions of the nucleus basalis of Meynert in monkeys appear to spare delayed response performance with short delays and instead cause attentional performance deficits (Voytko et al., 1994). Since systemic drug administration or lesions cholinergic nuclei innervating cerebral cortex could have manifold effects on the distributed brain circuitry that subserves various components of these behavioral tasks, deficits in cognitive control and WM highlighted by the studies summarized above do not necessarily indicate deficits in WM circuitry in the PFC or alterations in PFC persistent activity that maintains WM representations.

However, other reports have addressed the role of cholinergic innervation locally in the PFC in WM and other PFC-dependent cognitive tasks. Baxter's group reported an intriguing finding: cholinergic deafferentation, by injection of an immunotoxin based on saporin in the PFC of rhesus monkeys, resulted in a specific and selective deficit in spatial delayed response, but not in other demanding tasks that engaged attention but did not require WM, such as strategy implementation, object-in-place scene learning, or reward-based decision-making as assessed by reinforcer devaluation (Croxson et al., 2011). Other evidence about the role of ACh neuromodulation during delayed response tasks comes from the neurophysiology of the nucleus basalis. In monkeys engaged in spatial delayed responses, most nucleus basalis neurons were active only during the choice and reward phases of the task, and the proportion of neurons responding during the delay period was far less prominent (Richardson and DeLong, 1986). Richardson and DeLong further reported that nucleus basalis neuronal activity in response to stimuli depended on the task context, but that the activity of these neurons was related to rewarding or aversive stimuli and cues that predict them (Richardson and DeLong, 1991). Interestingly, in macaques, intermittent stimulation of the nucleus basalis improves performance in a WM task, while continuous stimulation degrades performance (Liu et al., 2017). A brief stimulation of cholinergic fibers has been shown to cause long lasting modulation of hippocampal and cortical activity stimulation (Krnjević et al., 1981; Cole and Nicoll, 1983; McCormick and Prince, 1986), mediated by the modulation of the M-current, so named because of its inhibition by muscarinic stimulation (Brown and Adams, 1980). The M-current is generated by voltage-gated KCNQ potassium channels and it counteracts overexcitability upon neuronal depolarization; its inhibition by muscarinic receptors causes an increase in excitability of neurons.

\section{MUSCARINIC MODULATION OF PFC NEUROPHYSIOLOGY AND PERSISTENT ACTIVITY}

There have been fewer studies describing the neurophysiological effects of muscarinic modulation in primates. Muscarinic blockade disrupts attentional modulation of cortical activity in primary visual cortex but nicotinic blockade, while reducing V1 excitability, did not affect attentional modulation (Herrero et al., 2008). Herrero et al. (2008) also reported that muscarinic antagonist scopolamine, in addition to reducing the overall activity of PFC neurons, reduced the attentional component of V1 neuronal firing. Herrero et al. (2008) also found that ACh increased the activity of V1 neurons, and at low doses, enhanced neuronal attentional selectivity. However, at higher doses ceiling effects appeared due to non-specific increase in activity that disrupted attentional modulation. One point that emerges from this is that the actions of $\mathrm{ACh}$ in $\mathrm{V} 1$ appear to be uniformly excitatory, an observation that will be pertinent to our discussion of ACh actions in PFC later. Consistent with this effect of muscarinic receptors in attentional modulation, muscarinic receptor blockade by systemic and local infusion of scopolamine in macaque intraparietal cortex, including the lateral intraparietal area and area 7a, produced a deficit in covert orienting in a cued stimulus detection task (Davidson et al., 1999; Davidson and Marrocco, 2000). A salient stimulus appeared in one of two previously cued locations and monkeys were trained to manually respond to the stimulus onset for reward. Attention was captured by changing the luminance of one of the cues prior to the appearance of the stimulus. Analysis of reaction times after scopolamine infusion demonstrated that covert attentional orienting was compromised.

Miller and Desimone (1992) recorded neuronal activity with systemic muscarinic blockade in the inferotemporal cortex during the performance of a delayed match-to-sample recency memory task with sequential delayed presentations of multiple stimuli after a test stimulus. The rewarded response was a lever release when a succeeding stimulus matched the test stimulus. Systemic scopolamine administration was deleterious to task performance, demonstrating the ACh actions through muscarinic receptors promoted recency memory. Surprisingly, this performance deficit was not accompanied by commensurate changes in the stimulus related activity of inferotemporal neurons. The number of neurons that showed selectivity for match vs. non-match stimuli was not significantly affected by muscarinic blockade. However, when compared with placebo, scopolamine administration caused paradoxical increases in stimulus responsive neuronal activity compared with baseline activity (Miller and Desimone, 1992). This increased stimulus responsivity did not change quantifiable task-related information in the neuronal activity. Thus, it appears that the effects of muscarinic blockade on task performance were not explained by changes in inferotemporal cortical activity.

Another study examined the effects of systemic injections of scopolamine on the activity of macaque PFC neurons (Zhou et al., 2011) engaged in an oculomotor delayed response task (Hikosaka and Wurtz, 1983; Funahashi et al., 1989) with varying distractor load (Figure 2). Delay period activity was suppressed after scopolamine administration, and behavioral performance degraded (Figure 2A) with small increases in saccade reaction times and saccade end-point dispersion. Interestingly, the performance degradation due to scopolamine was independent of distractor load during the trial (Figure 2A). The effects of muscarinic blockade were contingent upon the presence of a delay, whereby visually guided saccade performance (zero second delay) was unaffected. While scopolamine had modest effects on overall neuronal activity in the PFC, it significantly affected 


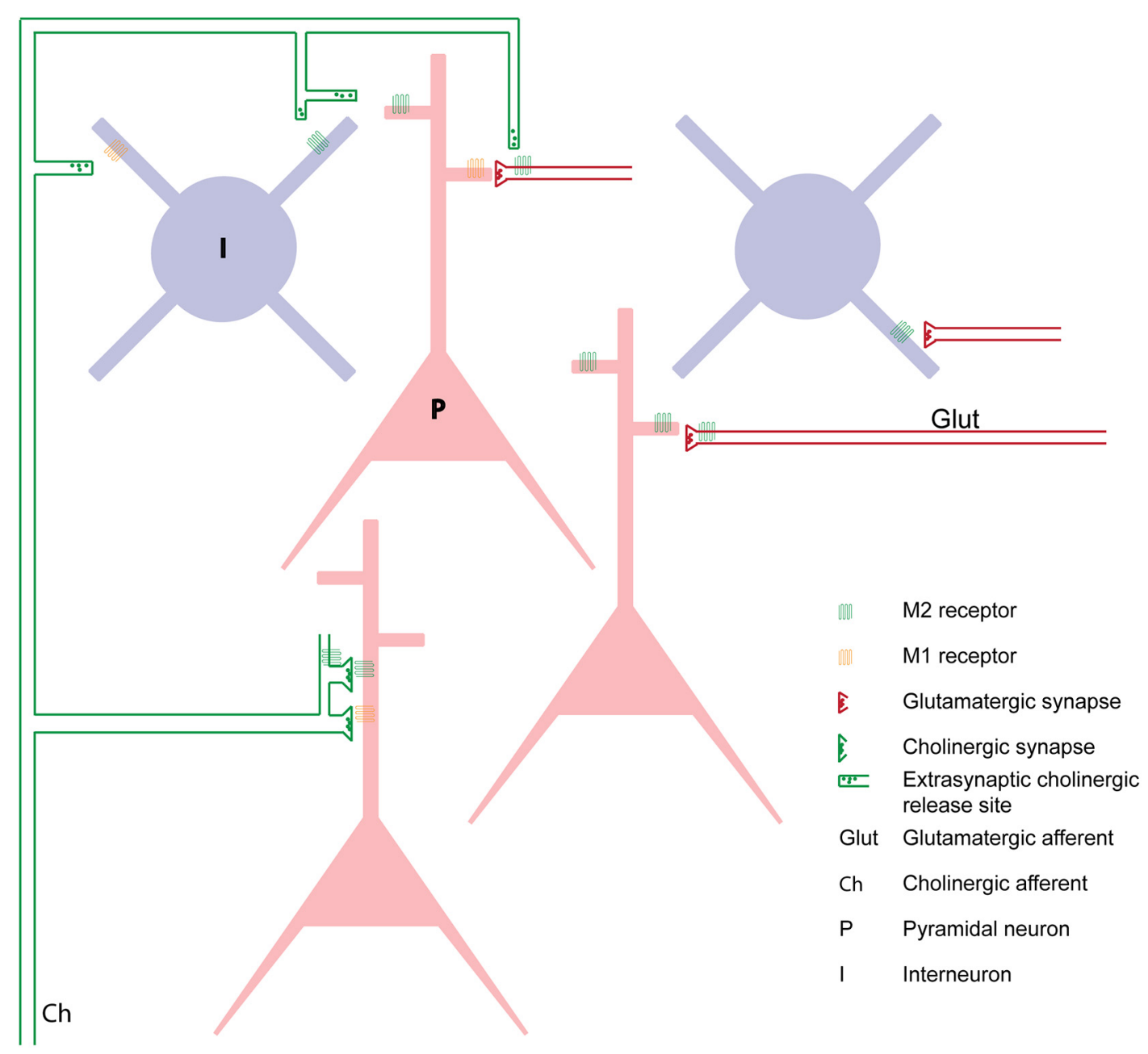

FIGURE 1 | Schematic showing the localization of muscarinic receptors on PFC neurons and their relationship to cholinergic and glutamatergic innervation based on data from Mrzljak et al. (1993) and Medalla and Barbas (2012). M1Rs are localized on dendritic shafts of pyramidal and interneurons, and on the spines of pyramidal neurons where they are apposed to glutamatergic synapses. Cholinergic synapses are mainly found on dendritic shafts, while extrasynaptic cholinergic release sites on cholinergic axons result in diffuse volume transmission to influence muscarinic receptors on PFC neurons. M2Rs are found on postsynaptic dendritic spines of pyramidal neurons and on dendritic shafts of interneurons. M2Rs are also found on presynaptic terminals of glutamatergic afferents in PFC and as autoreceptors on cholinergic terminals.

the delay period activity after visual stimulus presentation (Figure 2B). The authors also found that stimulus-related activity during the presentation of the peripheral cue in the delayed response task was comparatively unaffected, indicating that sensory stimulus processing in the PFC was not affected. Zhou et al. (2011) also tested the effects of scopolamine on PFC activity and performance in a delayed match/non-match-toposition task. The monkeys reported whether a second cue, presented after a short delay, was at the same or different location with respect to the first cue. They found that scopolamine's effects were not idiosyncratic to the oculomotor delayed response paradigm and manifested in the delayed match-to- position task also, whereby memory period persistent activity encoding the position of the first cue was diminished by systemic muscarinic blockade. Further, in this task, the authors found that, when the first stimulus was presented outside the neuron's response field and the second stimulus appeared within the neuron's response field, there was elevated activity in the delay period prior to the appearance of the second stimulus which reflected covert anticipation of the onset of the second stimulus in the response field. Muscarinic blockade diminished this anticipatory memory period activity. Thus, systemic muscarinic blockade had pronounced effects on PFC persistent activity representing the remembered location of a target and disrupted mnemonic performance.

The results of Zhou et al. (2011) indicated that muscarinic blockade reduces activity in PFC, but since that study employed systemic injections, it could not be determined if this effect was due to blockade of local PFC muscarinic receptors or due to network consequences of muscarinic blockade elsewhere in the brain. Our group has conducted experiments on the effects of local muscarinic blockade using microiontophoresis 

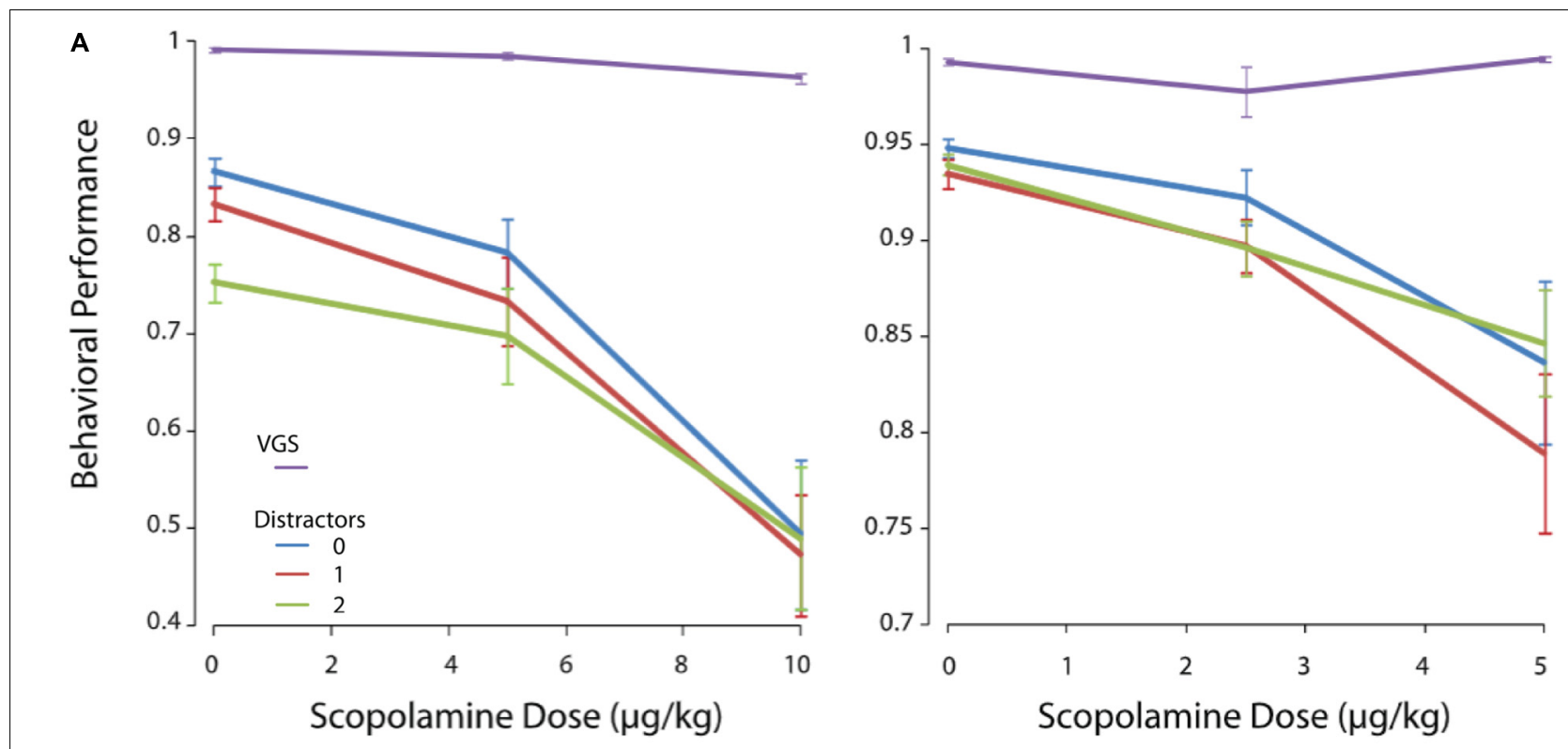

B

Control

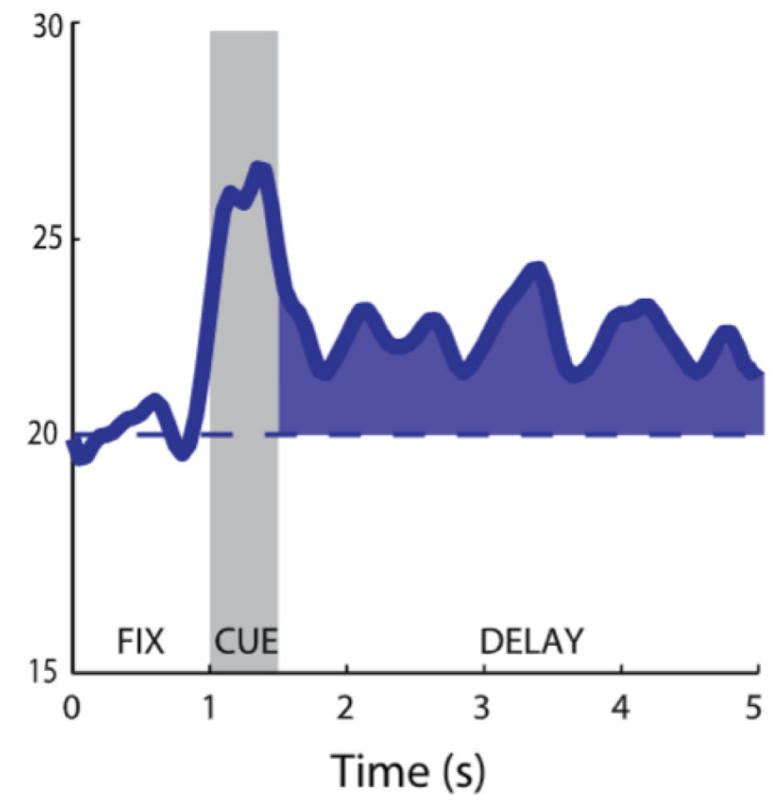

Scopolamine

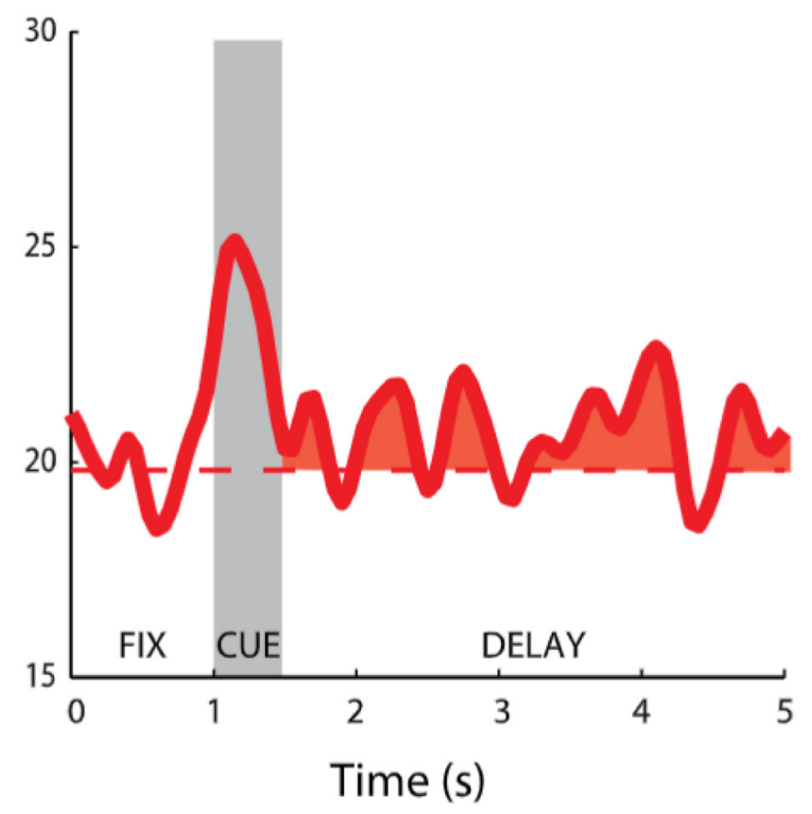

FIGURE 2 | Effects of systemic scopolamine administration on oculomotor delayed response performance and delay activity of PFC units. Adapted from Zhou et al. (2011). (A) Behavioral performance in the oculomotor delayed response task for two monkeys after scopolamine infusion at various doses. Purple, visually guided saccades ( 0 s delay); Blue, 0 distractors during delay; Red, 1 distractor during delay; Green, 2 distractors during delay. (B) Systemic scopolamine administration reduces delay period persistent activity of PFC neurons. Modified with permission from Journal of Neurophysiology.

on PFC neuronal activity while monkeys performed randomly interleaved pro- and antisaccades (Figure 3A), where the current trial rule had to be maintained in WM (Major et al., 2015). The pro- and antisaccade task is dependent of the integrity of dorsolateral PFC (Condy et al., 2007; Koval et al., 2011), and deficits in antisaccade performance are diagnostic indicator of the integrity of the PFC (Everling and Fischer, 1998). In the version of the task employed by Major et al. (2015), the rule cue was briefly presented, and had to be remembered through the memory period (Figure 3A). Persistent activity of PFC neurons encodes the task rule through this memory period (Skoblenick and Everling, 2012; Vijayraghavan et al., 2017). Microiontophoresis employs small electrical currents to eject charged moieties and drugs from the recording electrode 
A

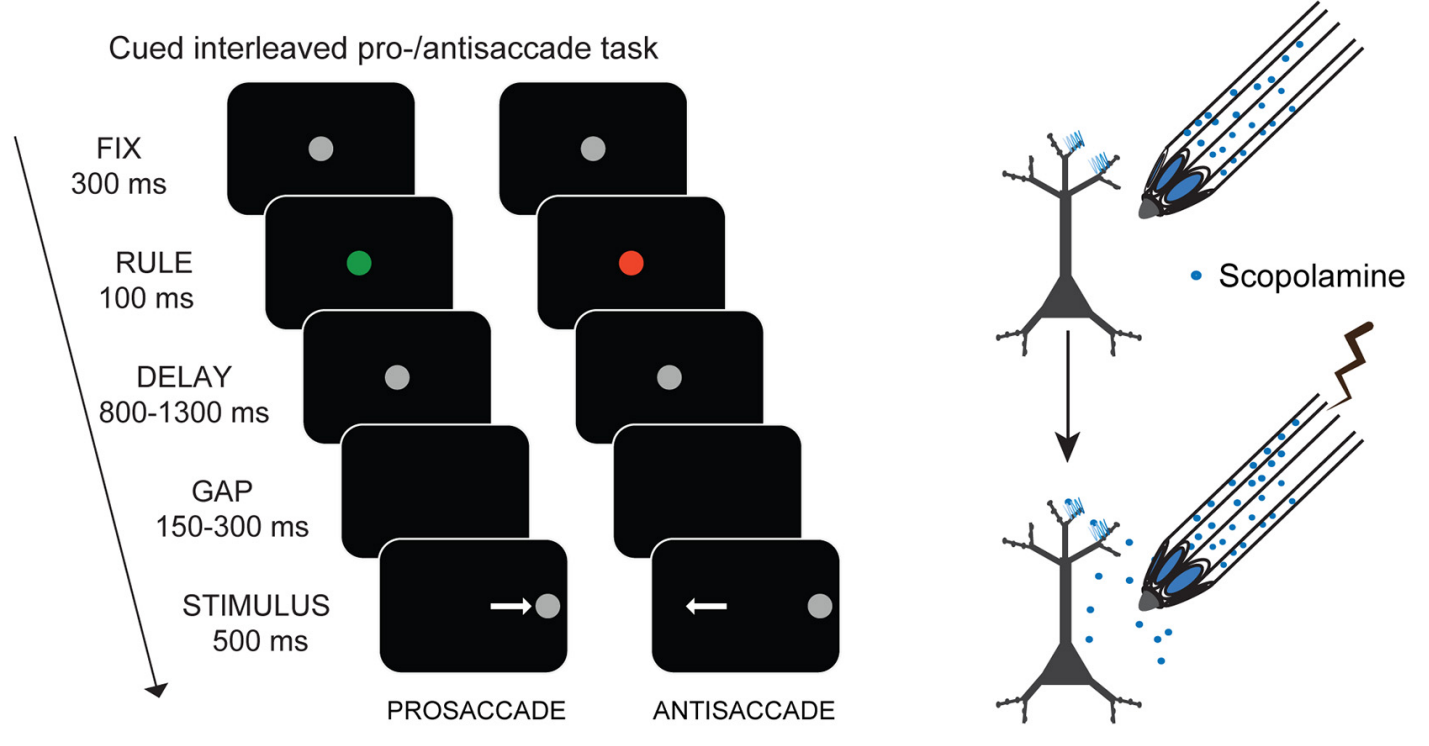

B
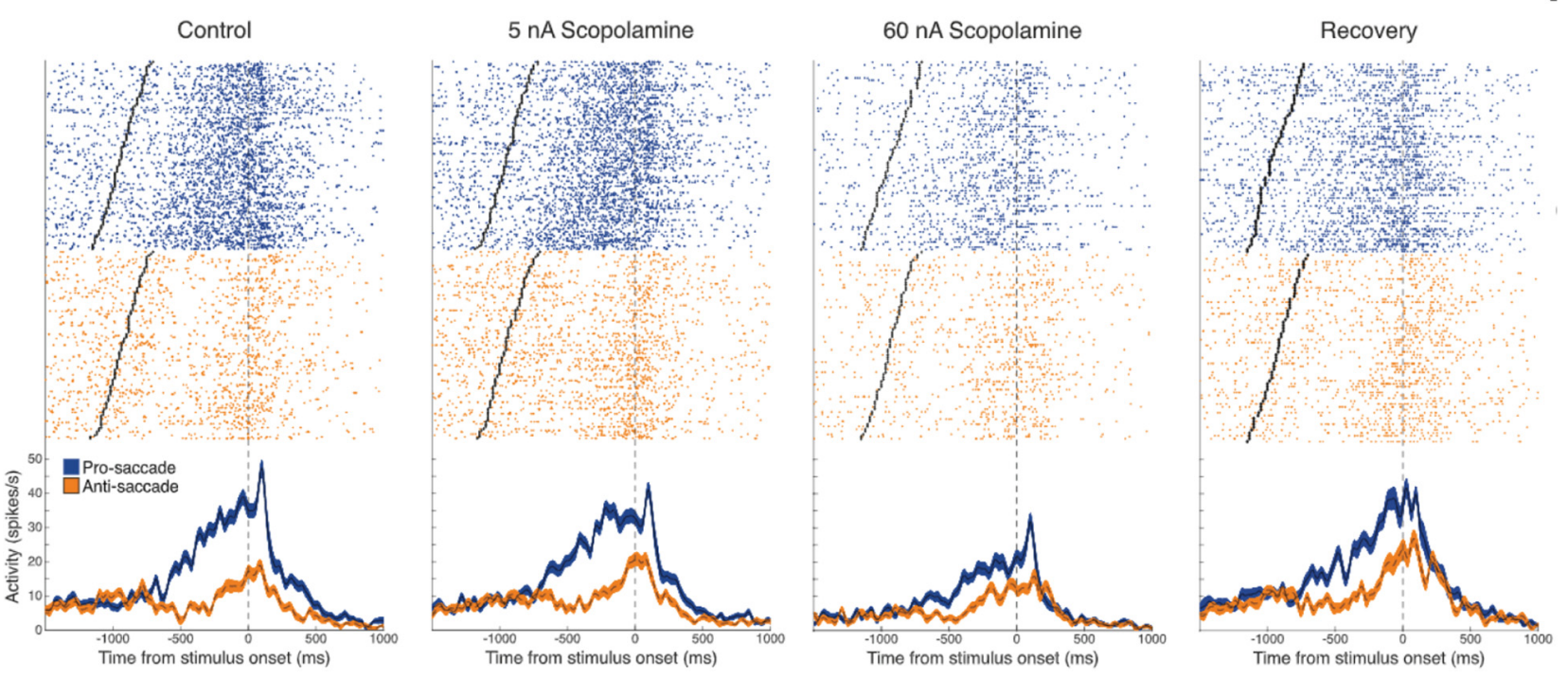

FIGURE 3 | Effects of local delivery of muscarinic antagonist scopolamine by microiontophoresis on PFC activity during pro- and antisaccade task. Adapted from Major et al. (2015). (A) Pro- and antisaccade task structure is shown. After central fixation, the fixation spot changes to a colored rule cue which flashes briefly. Subsequently the spot becomes white again. After a delay wherein the trial rule, based on the color of the rule cue, is maintained in WM, the fixation spot disappears, and after a brief gap, the peripheral stimulus appears left or right of the fixation spot. The subject makes a saccade toward (prosaccade) or away (antisaccade) from the spot, based on the current trial rule. Trial temporal structure are also shown. Illustration on the right shows the recording and iontophoresis technique. (B) Microiontophoresis of increasing doses of scopolamine cause increasing suppression of the activity of a PFC neuron that has delay-period activity preferring the pro-saccade rule. Right panel shows recovery after cessation of drug application.

(Hicks, 1984). The currents employed in these in vivo studies are on the order of $\sim 100 \mathrm{nA}$ and are not expected to elicit extraneous electrophysiological effects on the recorded neurons. Moreover, usually, the quantities of drugs ejected are not enough to elicit behavioral effects. Major et al. (2015) found that local stimulation of muscarinic receptors dose-dependently and monotonically suppressed the activity of a majority of PFC neurons recorded during the rule WM task performance, and concomitantly degraded all forms of task-related neuronal selectivity, including WM for the rule (Figure 3B), peripheral stimulus selectivity and perisaccadic activity. Thus, some of the effects of systemic muscarinic blockade described by Zhou et al. (2011) would appear to be explained by local blockade of muscarinic receptors in PFC. In contrast to Zhou et al. (2011), we found that peripheral visual stimulus selectivity was also reduced upon local scopolamine application. These differences could be due to concentration differences due to systemic application versus local drug ejection or differences in the behavioral task 
structure. In the interleaved rule-based antisaccade task, activity of PFC neurons is differentially modulated by the rule prior to the onset of the peripheral stimulus. These prestimulus activity differences are, perhaps in some respects, analogous to the anticipatory activity observed in the delayed match-to-position task in Zhou et al. (2011) and may convolve with visual stimulus responsivity accordingly.

Recently, stimulation of nicotinic $\alpha 4 \beta 2$ receptors was also examined in monkey PFC during spatial delayed response task performance (Sun et al., 2017). The authors found $\alpha 4 \beta 2$ receptor stimulation also augmented PFC delay period persistent activity in the oculomotor delayed response task and improved the memory period spatial tuning of these neurons in that period. Moreover, in a variant of that task where a distractor was presented during the delay period, $\alpha 4 \beta 2$ receptor stimulation shielded neuronal spatial tuning during the delay period from the effects of the distractor. $\alpha 4 \beta 2$ receptor stimulation did not affect sensory activity related to the peripheral visual stimulus or response-related perisaccadic activity at the end of the trial. However, $\alpha 4 \beta 2$ agonism also enhanced the activity of neurons that had activity related to central gaze fixation. Another report from the Arnsten group showed that iontophoretic stimulation of $\alpha 7$ nicotinic receptors enhanced NMDA-dependent persistent activity of PFC neurons (Yang et al., 2013). An $\alpha 7$ receptor agonist augmented delay period activity and spatial tuning of monkey PFC neurons during spatial delayed response, an effect which could be reversed by an $\alpha 7$ receptor antagonist. Interestingly, $\alpha 7$ receptor stimulation did not have appreciable effects on peripheral stimulus-related activity and instead facilitated and synergized with the actions of NMDA NR2B receptors on PFC neurons to influence delay period persistent activity.

Thus, the findings regarding muscarinic blockade of neuronal selectivity for the peripheral visual stimulus and perisaccadic selectivity in Major et al. (2015) contrast with analysis of the effects of $\alpha 4 \beta 2$ nicotinic receptor stimulation on stimulusselective and perisaccadic neurons in Sun et al. (2017) and stimulus-selective activity after $\alpha 7$ receptor stimulation from Yang et al. (2013). We found that muscarinic blockade reduces selectivity for all task attributes in PFC neurons, including visual stimulus and saccade direction selectivity, having a comprehensive disruptive effect on PFC neuronal task engagement. Thus, nicotinic receptor subtypes in PFC appear to be more specialized in their actions on prefrontal circuitry that generates and maintains persistent delay activity, whereas general muscarinic receptor modulation appears to affect the gamut of observable PFC task-related activity.

Since muscarinic antagonism engendered such pronounced suppression of the activity of PFC neurons during WM, it would be expected that muscarinic and cholinergic agonists may enhance persistent activity and WM representations. There is some evidence that muscarinic stimulation can sustain persistent activity through intrinsic mechanisms (Egorov et al., 2002). Rat entorhinal cortical neurons, in the presence of the cholinergic agonist carbachol, respond to current pulse stimulation with long lasting activity that is reminiscent of persistent activity displayed by cortical neurons in WM tasks (Figure 4A). This carbachol-induced response is graded with increasing discharge rate after successive stimulations. The persistent responses could be blocked by general muscarinic blockade (Figure 4A) or by pirenzepine, an antagonist preferentially blocking M1Rs. Synaptic stimulation in concert with carbachol application also generated persistent spiking accompanied by the generation of nifedipine-sensitive $\mathrm{Ca}^{2+}$ plateau potentials. Thus, ACh, through muscarinic mechanisms, could facilitate persistent activity in cortical neurons through cell-autonomous intrinsic mechanisms that, in concert with stimulus evoked responses, could engender WM representations. However, traditionally, WM persistent activity is thought to be a network phenomenon, generated by slow reverberatory synaptic activity in a network of neurons (Wang, 2001). Whether this intriguing phenomenon that manifested in rodent entorhinal cortical slices would also occur in vivo in primate PFC was not clear.

To clarify whether carbachol could induce or augment persistent activity in PFC during WM task performance, our group conducted experiments where we microiontophoretically applied carbachol on PFC neurons in rhesus monkeys performing the rule-memory guided pro- and antisaccade task (Major et al., 2018). Surprisingly, we found that carbachol had mixed effects on neuronal physiology and persistent activity (Figure 4B). Carbachol application significantly excited roughly half the PFC neurons recorded, while $\sim 40 \%$ of neurons were inhibited. Moreover, carbachol increased the activity of broadspiking presumed excitatory pyramidal neurons, while effects on excitability of narrow-spiking presumed mainly parvalbuminpositive interneurons were more varied. Rule encoding in the persistent activity during the delay epoch was diminished by carbachol application, especially at higher doses. This decrease in rule selectivity occurred notwithstanding the direction of changes in excitability of the neurons. It is noteworthy that carbachol is a general cholinergic agonist that has agonist activity at both muscarinic and nicotinic receptors. However, as discussed earlier, studies heretofore report that stimulation of the major nicotinic receptor subtypes in PFC appear to be generally excitatory (Yang et al., 2013; Sun et al., 2017), suggesting that the physiological actions of carbachol in Major et al. (2018) were mediated by muscarinic receptors.

\section{NEUROMODULATION OF PFC PERSISTENT ACTIVITY BY MUSCARINIC RECEPTOR SUBTYPES}

Given the pervasiveness of scopolamine-induced suppression of PFC neurons described above (Major et al., 2015), and that some or all of the effects of PFC carbachol stimulation were mediated by muscarinic receptors (Major et al., 2018), the question arises as to which muscarinic receptor subtypes contributed to the various physiological effects on persistent activity and task-selectivity changes caused by these cholinergic manipulations.

As discussed previously, M1Rs are the dominant muscarinic receptor subtype expressed in PFC. Since they are localized postsynaptically at asymmetric synapses on dendritic spines of pyramidal neurons, M1R constitutes an attractive candidate for mediating the general suppression of PFC by muscarinic 
A

A

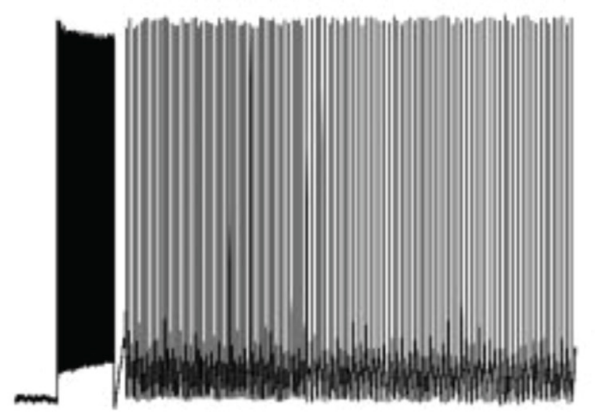

B Control

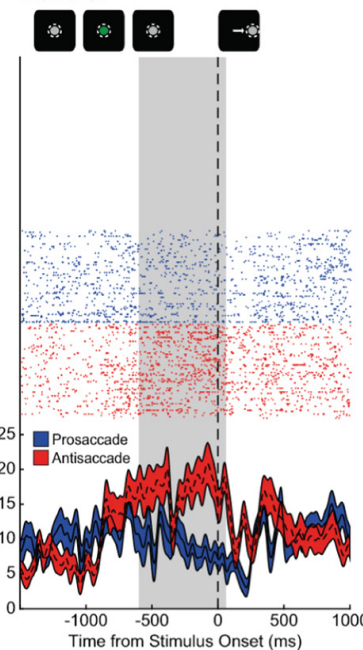

Control

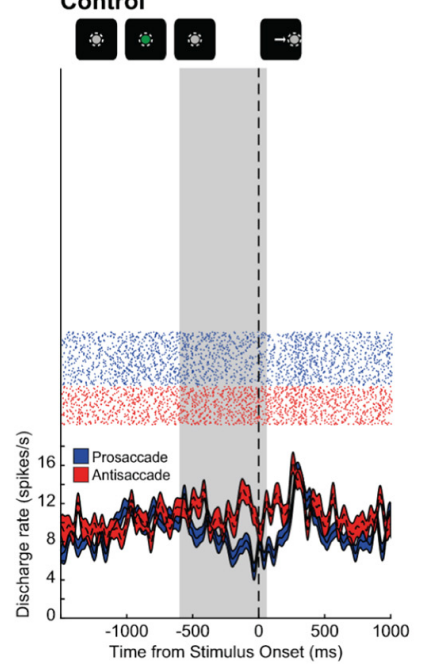

Carbachol

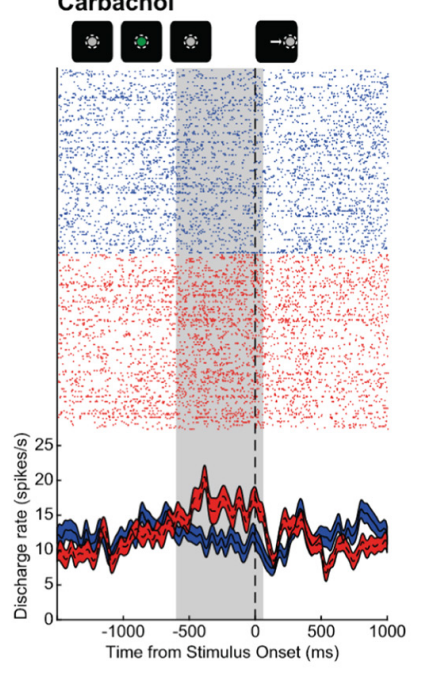

Carbachol

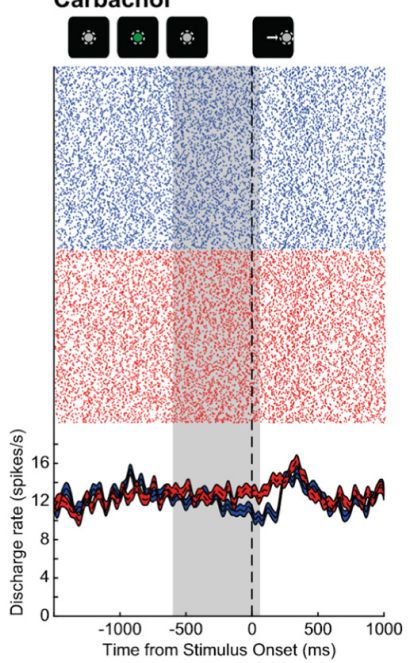

\section{Atropine}
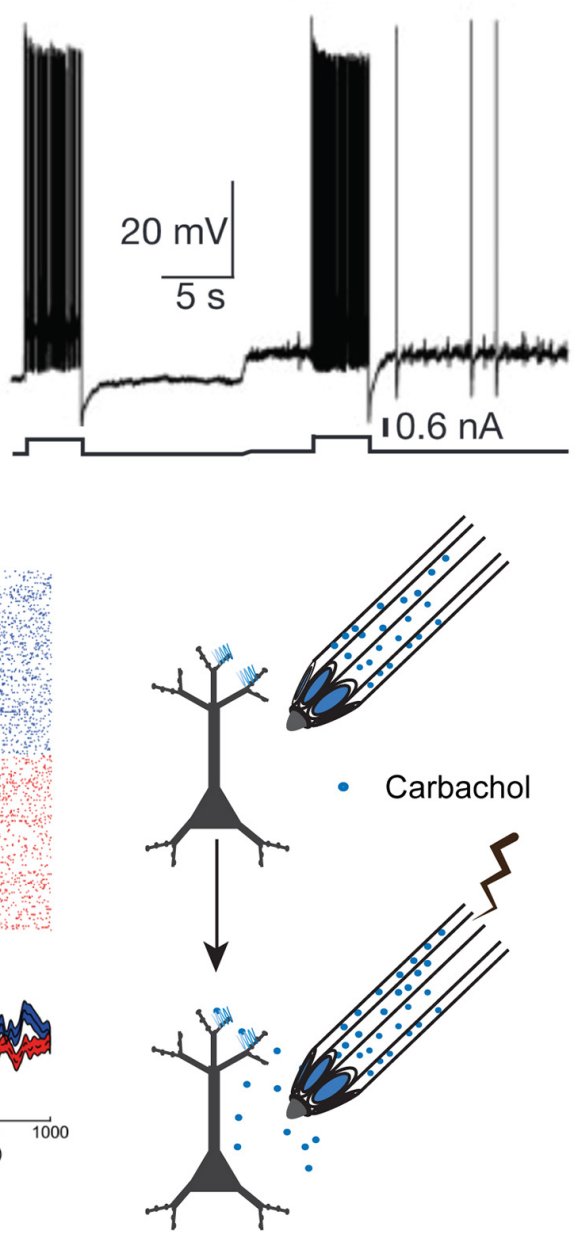

FIGURE 4 | Influence of cholinergic agonist carbachol on persistent activity. (A) adapted from Egorov et al. (2002); (B) adapted from Major et al. (2018). (A) Example of persistent activity evoked in a rat entorhinal cortical neuron by a current pulse in the presence of carbachol. Neuronal discharge persists after cessation of stimulus, and after muscarinic blockade, and after muscarinic blockade. Neuronal discharge persists after cessation of stimulus in the presence of carbachol, but not during blockade of muscarinic receptors. (B) Illustration on the right shows experimental design of neuronal recording and carbachol iontophoresis. Shown on the left is the activity of two PFC neurons (top and bottom panels) with persistent rule-selective activity during the delay period is shown during control (left) and during carbachol (right) application. Carbachol attenuated WM activity for the antisaccade rule in the neuron shown in the top panel, while the activity of the neuron in the bottom panel was augmented by carbachol, but selectivity for the trial rule in the delay period was nevertheless diminished. Gray area shows the last 600 ms of the delay period prior to fixation offset. Reproduced with permission from Nature Publishing group. 
blockade. M1R stimulation inhibits the M-current and can thereby increase cortical neuronal excitability (McCormick and Prince, 1986; Marrion, 1997; Shirey et al., 2009; Young and Thomas, 2014). M1Rs and KCNQ channels are both expressed on dendritic spines and dendrites in layer III pyramidal neurons of PFC (Galvin et al., 2020b). An allosteric potentiator of M1R signaling increased the activity of medial PFC neurons in rodents in vivo and restored reversal learning in a transgenic model of Alzheimer's disease (Shirey et al., 2009). A selective M1R antagonist and scopolamine both produce antidepressant actions in rodents due to actions in medial PFC (Navarria et al., 2015). M1R knockout mice have been found to have selective deficits in non-match-to-sample tasks while, surprisingly, showing performance enhancement in match-to-sample tasks, with a reduction in theta burst stimulation, and long-term potentiation in mice (Anagnostaras et al., 2003). An M1R positive allosteric modulator was found to enhance cognitive task performance in macaques, including self-ordered spatial search, and an object retrieval detour task (Uslaner et al., 2013). M1R also mediates long-term excitability changes in striatal neurons ( $\mathrm{Lv}$ et al., 2017). KCNQ channels that generate the M-current are active near the action potential threshold (Brown and Adams, 1980), and inhibition of the M-current by pharmacological blockade of KCNQ channels increases PFC delay period activity during oculomotor delayed response (Wang et al., 2011). The M-current is dependent on PIP2 levels, which are regulated by phospholipase $\mathrm{C}$, downstream of $\mathrm{G}_{q}$ signaling (Suh and Hille, 2002, 2005, 2007; Suh et al., 2006). Since M1R is coupled to $G_{q}$ signaling and the inositol phosphate pathway (Popiolek et al., 2016; Maeda et al., 2019), it may be the main conduit for increasing neuronal excitability in primate PFC by inhibiting the M-current.

On the other hand, M1R could have inhibitory influences by direct activation of parvalbumin-positive interneurons (Yi et al., 2014). In rhesus macaque areas V1 and MT, the majority of parvalbumin-positive interneurons are found to express M1Rs (Disney and Aoki, 2008; Disney and Reynolds, 2014), although it is not clear if this is also the case in PFC. M1R activation leads to $\mathrm{Ca}^{2+}$ mobilization from intracellular stores through the IP3 receptor and this release of $\mathrm{Ca}^{2+}$ can transiently hyperpolarize neocortical neurons through the activation of calcium-activated SK potassium channels (Gulledge and Stuart, 2005). The transient suppression is usually followed by long lasting depolarization of the neuron. Metabotropic glutamate receptors also mobilize this IP3-receptor and SK channeldependent mechanism to cause transient suppression of cortical neurons as well (Hagenston et al., 2008). One confound in the interrogation of subtype-selective muscarinic actions has been the lack of subtype selectivity of orthosteric muscarinic agonists and antagonists, the ACh binding motif is conserved among the receptor subtypes (Jones et al., 2012; Jiang et al., 2014). Among the older generation of orthosteric compounds, some, such as the agonist $\mathrm{McN}-\mathrm{A}-343$ and the antagonist pirenzepine have a pharmacological preference for M1Rs (Mitchelson, 2012) but are not highly subtype-selective (Giachetti et al., 1986; Davies et al., 2001). Recently, however, a new class of M1R agents have been synthesized that show pharmacological activity by binding at allosteric sites on the receptor and show considerable subtype selectivity and clinical promise (Bubser et al., 2011). These comprise allosteric agonists and antagonists, that act on non-ACh receptor sites and activate or inhibit the receptor directly, and positive allosteric modulators, that do not activate the receptor alone, but in concert with endogenous ACh can augment the ACh response.

Recently, our group has tested the effects of M1Rs on persistent WM activity for rules in monkey PFC (Vijayraghavan et al., 2018). Microiontophoresis of a selective M1R allosteric agonist, VU0357017 (Lebois et al., 2010; Digby et al., 2012), M1Rpreferring agonist McN-A-343 and M1R-preferring antagonist pirenzepine were performed on PFC neurons engaged in the rule-memory guided pro- and antisaccade task described earlier (Figure 5A). Surprisingly, we found that M1R-selective allosteric agonist VU0357017 dose-dependently and strongly suppressed PFC neurons during task performance (Figure 5A). At lower dose ranges, about half of the PFC neurons tested were inhibited by the allosteric agonist, while at higher dose ranges, almost all (81\%) of neurons tested were inhibited. Application of the orthosteric agonist, McN-A-343, also induced substantial suppression of $\sim 60 \%$ of PFC neurons. Furthermore, application of the allosteric M1R agonist disrupted the rule selectivity of the persistent delay activity of many PFC neurons (Figure 5B), while a few neurons showing increases in persistent activity and increase in rule representation (Vijayraghavan et al., 2018). Interestingly, M1R blockade with pirenzepine (Figure 5B) also suppressed the activity of many PFC neurons (Vijayraghavan et al., 2018). However, the proportion of neurons that displayed suppression did not increase with higher doses and, at the population level was pirenzepine induced suppression was milder than that observed previously with general antagonist scopolamine and milder than the suppression with the high doses of the M1R-selective allosteric agonist. Moreover, in contrast to the effects of scopolamine, although application of the M1Rselective antagonist altered the rule-selectivity in the delay period activity in some individual PFC neurons, the rule selectivity at the level of the population was not significantly altered. M1R stimulation did not differentially affect narrow-spiking putative interneurons and regular-spiking putative pyramidal neurons, indicating that increased inhibition from parvalbumin-positive interneurons could not explain the physiological suppression caused by the agonist or antagonist.

In summary, these results indicated that M1R blockade could not account for the pervasive neuronal suppression and general disruption of task selectivity that was observed with general muscarinic blockade with scopolamine (Major et al., 2015). Further, M1R overstimulation unexpectedly has strong suppressive effects on WM activity in PFC.

Another recent study examined M1R modulation of PFC WM activity during oculomotor delayed response performance in aged monkeys (Galvin et al., 2020b). This study also found that high doses of the same allosteric M1R agonist, VU0357017, suppressed PFC WM activity, but in contrast with Vijayraghavan et al. (2018), low doses of the allosteric agonist enhanced PFC persistent activity (Figures 6A,C). Galvin et al. (2020b) also reported that systemic administration of another M1R positive 


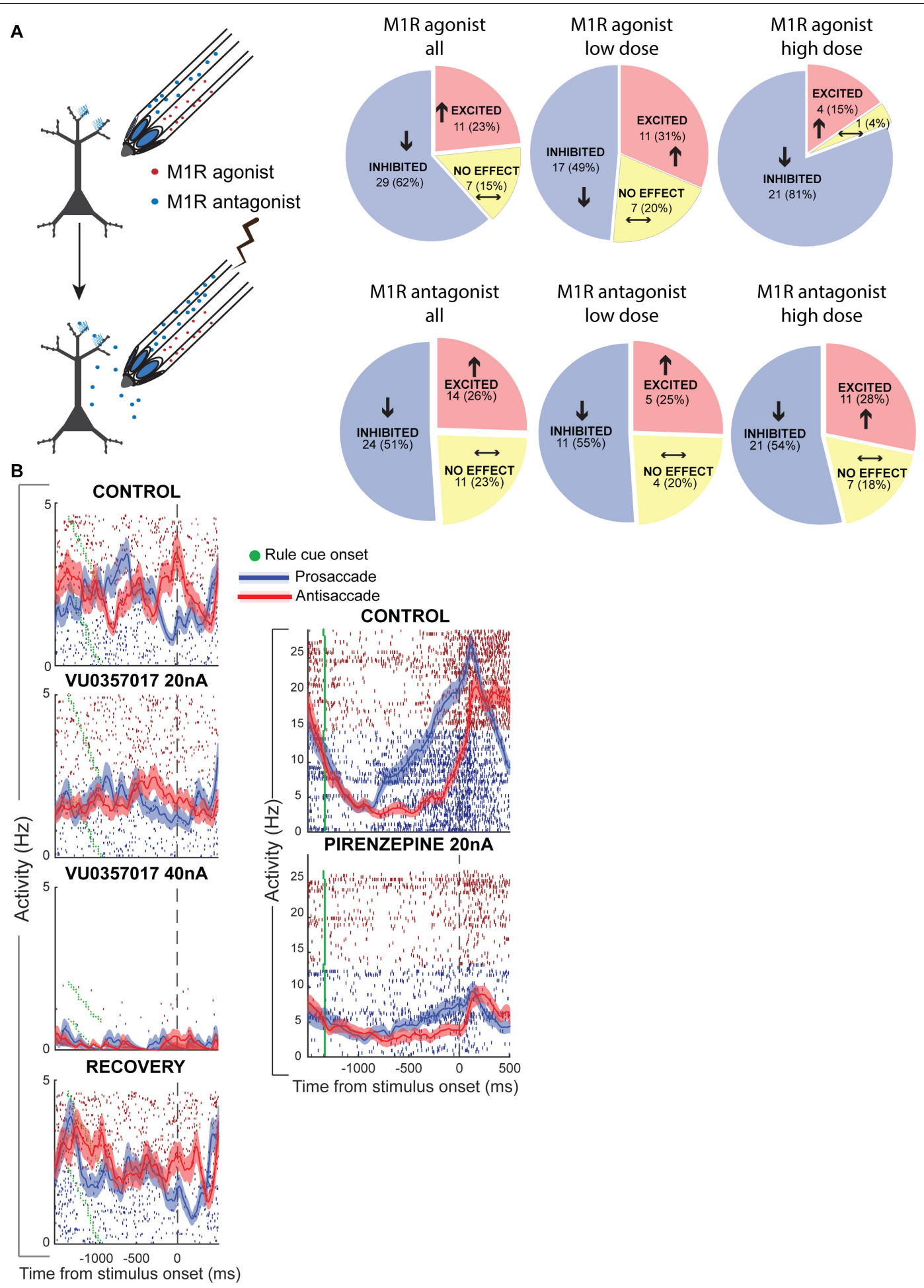

FIGURE 5 | Muscarinic M1R modulation of rule WM in monkey PFC. Adapted from Vijayraghavan et al. (2018). (A) Experimental design of iontophoresis and recording experiments shown on the left. Effects of M1R allosteric agonist, VU0357017 (top panel) and M1R antagonist pirenzepine on neuronal physiology in PFC. Pie-charts show number of neurons in the population that were significantly inhibited, excited or unaffected by drug application. Left-most panel shows the net drug effect on neurons tested at any (both low and high) doses of the M1R agonist. Middle panel, low doses; Right panel, High doses. (B) Left panel shows the effects of two doses of the M1R agonist on a PFC neuron with delay period activity selective for antisaccades over prosaccades. High dose of the M1R agonist strongly suppresses the neuron and disrupts rule selectivity in the delay period. Recovery shown in bottom left panel. Right panel shows the activity of a PFC neuron before and during application of M1R antagonist pirenzepine. This neuron showed ramping persistent activity during the delay period that was selective for prosaccades. M1R blockade inhibited this neuron and also diminished rule selectivity. Modified with permission from Elsevier (Neuron). 
A

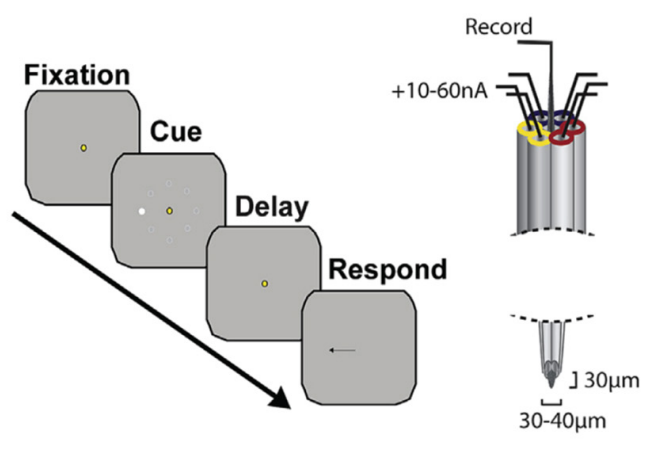

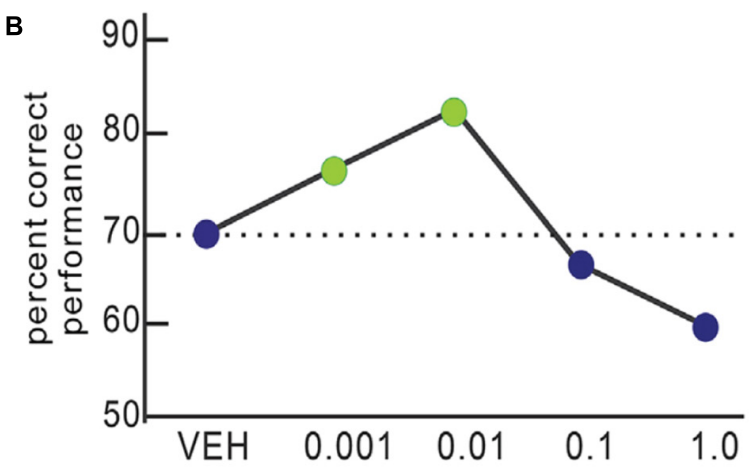

Dose VU0453595 ug/kg

C

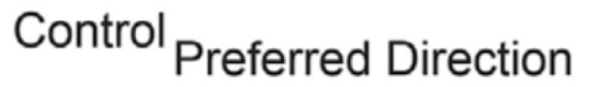

Nonpreferred Direction
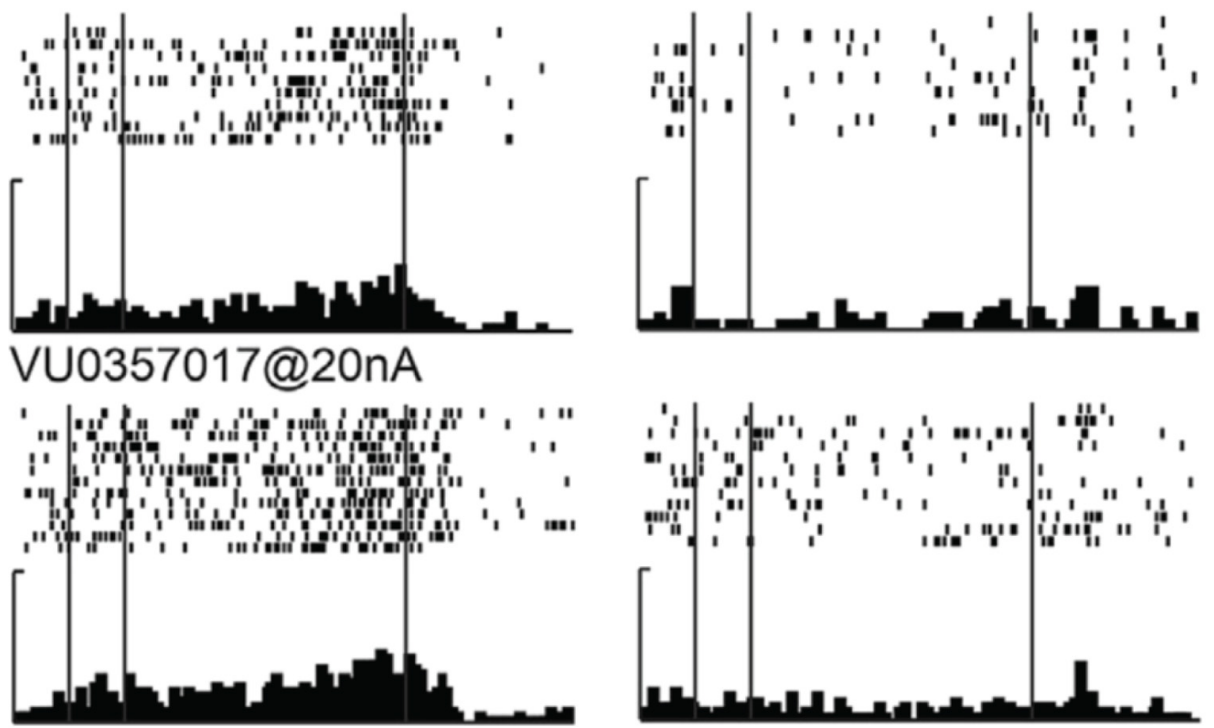

VU0357017@40nA
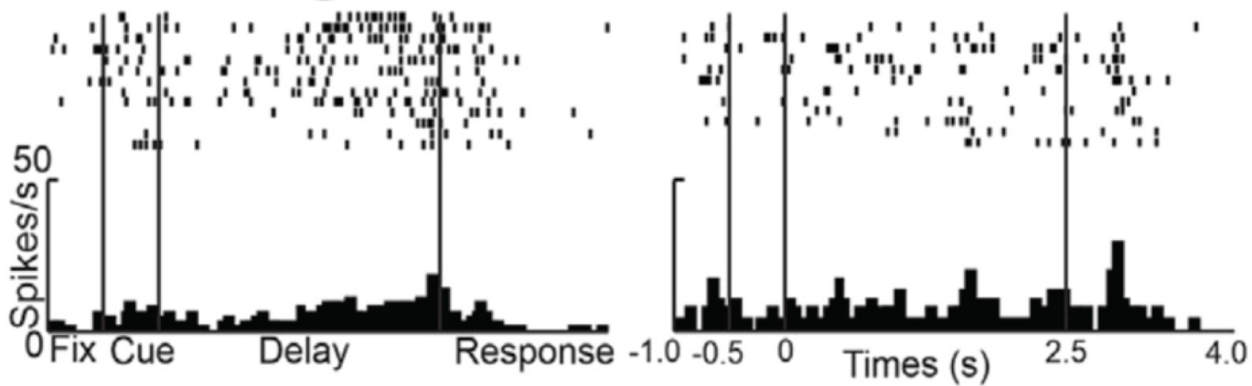

FIGURE 6 | Effects of M1R stimulation on spatial delayed response performance and delay period persistent activity. Adapted from Galvin et al., $2020 \mathrm{~b}$.

(A) Schematic of trial structure of oculomotor delayed response and iontophoresis technique from Galvin et al. (2020b). After central fixation, a peripheral cue briefly flashes at one of eight locations. The cue location is maintained in WM during the delay period, when central fixation continues to be maintained. At the end of the delay indicated by fixation spot offset, the subject makes a saccade to the remembered location. (B) Behavioral dose response curves for systemic administration of M1R positive allosteric modulator VU0453595 during spatial delayed response performance in by an aged monkey. M1R stimulation has an inverted-U effect on WM performance. WM performance degrades at doses higher than the optimal dose. (C) Microiontophoresis of increasing doses of M1 allosteric agonist, VU0357017 on persistent spatially tuned delay period activity of a PFC neuron. Left panel shows rasters and histograms for neurons preferred direction. Right panel shows rasters and histograms for neurons non-preferred direction. M1R agonist application at low dose enhances WM activity, while higher dose application suppresses the neuron. Reproduced with permission from Elsevier (Neuron). 
allosteric modulator in aged monkeys improved WM behavioral performance at low doses but disrupted performance at high doses (Figure 6B). They further reported that inhibiting the M-current could restore delay-related firing which had been suppressed by selective M1R antagonist, telenzepine.

The effects of different muscarinic actions on neuronal physiology in the PFC from the studies discussed above have been summarized in Table 1. These surprising results with M1R agonists point to the possibility that M1R overstimulation in primate PFC may trigger signaling mechanisms that lead to neuronal suppression. Thus, the actions of ACh in PFC in alert behaving primates may involve mechanisms that engender nontrivial suppression of cortical activity through M1Rs. Further the results in Vijayraghavan et al. (2018) suggest that the actions of ACh on M1R do not completely account for the suppressive effects of general muscarinic blockade on PFC neurons.

Several mechanisms may account for the suppression due to M1R overstimulation. One possibility is that M1R excitation of interneurons at high doses of stimulation leads to a suppression of PFC neurons. However, this is unlikely, as noted above because Vijayraghavan et al. (2018) reported that narrow-spiking putative parvalbumin positive interneurons were also equally suppressed by the agonist. This, of course, does not account for other classes of interneurons which are not narrow spiking, the increase in activity of which may well have caused suppression of the pyramidal neurons. Another possible mechanism for the inhibition may be SK potassium channel activation by intracellular $\mathrm{Ca}^{2+}$ mobilization due to M1R stimulation, as discussed elsewhere in this review (Gulledge and Stuart, 2005). It is noteworthy, that previous iontophoretic studies examining $\mathrm{G}_{q}$ protein-coupled receptors have found that stimulating these receptors has inhibitory effects on PFC neurons in primates and in some rodent studies. al adrenergic receptor stimulation suppresses delay period activity in a spatial delayed response task (Birnbaum et al., 2004) and $\mathrm{G}_{q}$ metabotropic glutamate receptor 1 was shown to increase inhibitory transmission in rat medial PFC, impairing decision-making (Sun and Neugebauer, 2011).

Galvin et al. (2020b) propose that suppression due to overstimulation of M1Rs could be the result of membrane hyperpolarization due to increase in the open state of KCNQ2 channels (Jentsch, 2000) due to M1R-mediated protein kinase C-cyclic AMP-protein kinase A signaling. Indeed, they show that retigabine, a positive allosteric modulator that preferentially targets KCNQ2 channels and increases the open state of the channels reduces persistent activity of PFC neurons. Future experiments must address the underlying mechanism involved in the suppression of persistent activity in the PFC by M1R overstimulation.

Vijayraghavan et al. (2018) also reported that M1R antagonist application suppressed roughly half of the PFC neurons tested even at the highest doses tested and did not systematically alter WM rule selectivity, in contrast with the uniform neuronal suppression and loss of task selectivity due to scopolamine (Major et al., 2015). This suggests that there are other muscarinic excitatory mechanisms independent of M1Rs active in the PFC. Vijayraghavan et al. (2018) proposed that there may be excitatory mechanisms based on M2R activation which may

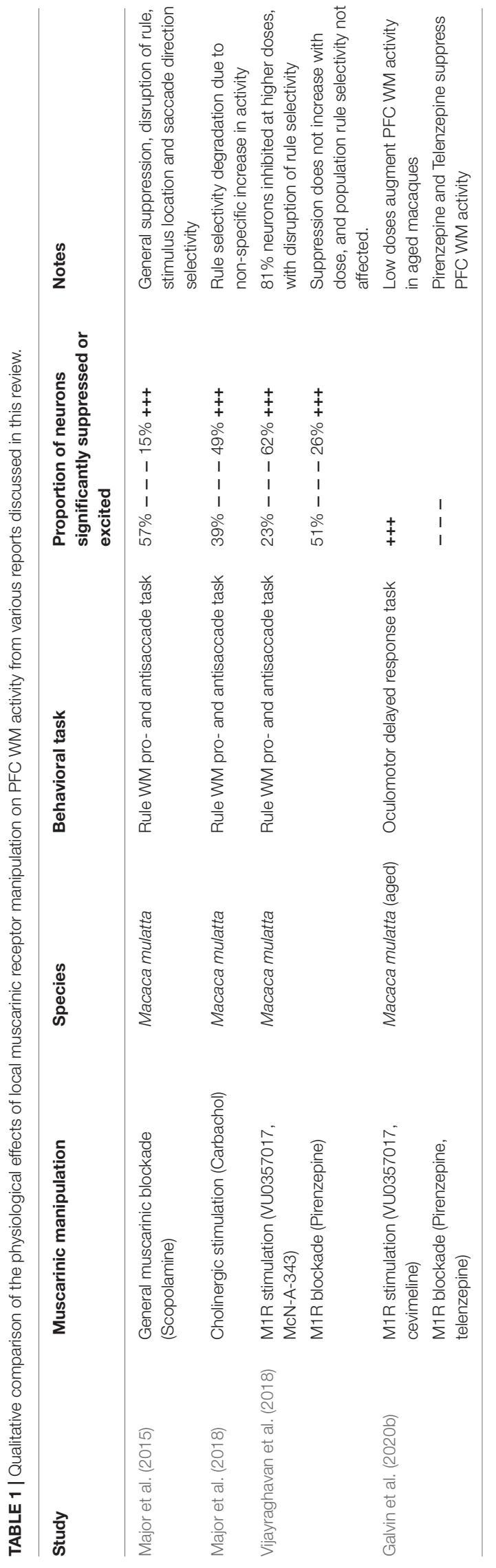


explain why M1R blockade does not replicate the efficacy of general muscarinic blockade in neuronal suppression and task selectivity. As discussed in this review, M2R is present postsynaptically in both pyramidal neuron dendritic spines and in the dendrites of interneurons. M2Rs are $\mathrm{G}_{i / o^{o}}$-coupled receptors, and previous microiontophoretic studies in monkey PFC have shown that stimulation of the dopamine D2 receptor, which is also coupled to $G_{i / o}$, can augment the activity of specific classes of PFC neurons during WM tasks (Wang et al., 2004; Vijayraghavan et al., 2016, 2017; recently reviewed by Ott and Nieder, 2019). Thus, in addition to their documented role in autoinhibition and heteroinhibition as presynaptic receptors (Murakoshi, 1995), post-synaptic M2R signaling may lead to increase in PFC neuronal excitability and augmentation of persistent activity. In support of this hypothesis, preliminary data from our group suggests that M2R antagonism suppresses the delay activity of PFC cells engaged in the rule-memory guided pro- and antisaccade task. Future studies with local application of M1R-selective allosteric antagonists, like VU0255035, and M2Rselective agonists and antagonists in PFC will help resolve these apparent paradoxes of muscarinic actions on PFC WM circuits.

These results with M1R compounds in monkey PFC are of particular interest, because M1R-selective agents are being actively investigated for cognitive enhancement and amelioration of cognitive deficits in neuropsychiatric disorders (Bubser et al., 2011; Thiele, 2013; Carruthers et al., 2015). M1R based therapeutics, such as KarXT, a coformulation of M1R agonist xanomeline and trospium, a peripheral muscarinic M2R antagonist that ameliorates non-target side effects of xanomeline, are showing promising results in clinical trials for the treatment of schizophrenia (Brannan et al., 2019).

\section{REFERENCES}

Aigner, T. G., and Mishkin, M. (1993). Scopolamine impairs recall of one-trial stimulus-reward association in monkeys. Behav. Brain Res. 54, 133-136. doi: 10.1016/0166-4328(93)90071-w

Aigner, T. G., Mitchell, S. J., Aggleton, J. P., DeLong, M. R., Struble, R. G., Price, D. L., et al. (1987). Effects of scopolamine and physostigmine on recognition memory in monkeys with ibotenic-acid lesions of the nucleus basalis of Meynert. Psychopharmacology 92, 292-300. doi: 10.1007/bf00210833

Aigner, T. G., Mitchell, S. J., Aggleton, J. P., DeLong, M. R., Struble, R. G., Price, D. L., et al. (1991). Transient impairment of recognition memory following ibotenic-acid lesions of the basal forebrain in macaques. Exp. Brain Res. 86, 18-26. doi: 10.1007/bf00231036

Anagnostaras, S. G., Murphy, G. G., Hamilton, S. E., Mitchell, S. L., Rahnama, N. P., Nathanson, N. M., et al. (2003). Selective cognitive dysfunction in acetylcholine M1 muscarinic receptor mutant mice. Nat. Neurosci. 6, 51-58. doi: 10.1038/ nn992

Arnsten, A. F. T., Wang, M. J., and Paspalas, C. D. (2012). Neuromodulation of thought: flexibilities and vulnerabilities in prefrontal cortical network synapses. Neuron 76, 223-239. doi: 10.1016/j.neuron.2012.08.038

Aston-Jones, G., and Bloom, F. (1981). Activity of norepinephrine-containing locus coeruleus neurons in behaving rats anticipates fluctuations in the sleep-waking cycle. J. Neurosci. 1, 876-886. doi: 10.1523/jneurosci.01-08-00876.1981

Barak, S. (2009). Modeling cholinergic aspects of schizophrenia: focus on the antimuscarinic syndrome. Behav. Brain Res. 204, 335-351. doi: 10.1016/j.bbr. 2009.04.006

Barak, S., and Weiner, I. (2006). Scopolamine induces disruption of latent inhibition which is prevented by antipsychotic drugs and an

\section{CONCLUSION}

In this review, we have discussed the neuromodulatory influence of the corticopetal cholinergic system through muscarinic receptors on primate PFC WM circuits that manifest persistent memory-related activity. The anatomical localization of these receptors shows exquisite specificity and correspondence with network connections within the PFC. Cortical muscarinic receptors play a pivotal role in arousal and brain state transitions, and their activation is necessary for the proper functioning of recurrent circuits in the PFC that generate persistent activity in WM tasks. Recent work shows that their role in primate PFC may be quite different from what would be expected from prior studies in other model systems like rodents and moreover, diverges from their role in sensory cortical areas. Further elucidation of muscarinic neuromodulation of PFC cognitive circuitry promises to be a rewarding endeavor for translational research and the development of new targets for the treatment of neuropsychiatric and neurological disorders.

\section{AUTHOR CONTRIBUTIONS}

SV and SE wrote and edited the manuscript. Both authors contributed to the article and approved the submitted version.

\section{FUNDING}

This research was supported by the CIHR grant FRN148365 to SE and the Canada First Research Excellence Fund to BrainsCAN.

acetylcholinesterase inhibitor. Neuropsychopharmacology 32, 989-999. doi: 10.1038/sj.npp.1301208

Barak, S., and Weiner, I. (2009). Towards an animal model of an antipsychotic drug-resistant cognitive impairment in schizophrenia: scopolamine induces abnormally persistent latent inhibition, which can be reversed by cognitive enhancers but not by antipsychotic drugs. Int. J. Neuropsychoph. 12, 227-241. doi: 10.1017/s14611457080 09176

Bartus, R. T., and Johnson, H. R. (1976). Short-term memory in the rhesus monkey: disruption from the anti-cholinergic scopolamine. Pharmacol. Biochem. Be. 5, 39-46. doi: 10.1016/0091-3057(76)90286-0

Baxter, M. G., and Crimins, J. L. (2018). Acetylcholine receptor stimulation for cognitive enhancement: better the devil you know? Neuron 98, 1064-1066. doi: 10.1016/j.neuron.2018.06.018

Birnbaum, S. G., Yuan, P. X., Wang, M., Vijayraghavan, S., Bloom, A. K., Davis, D. J., et al. (2004). Protein Kinase C overactivity impairs prefrontal cortical regulation of working memory. Science 306, 882-884. doi: 10.1126/science. 1100021

Brannan, S., Miller, A., Felder, C., Paul, S., and Breier, A. (2019). T106. KARXT: A M1/M4 preferring muscarinic agonist for the treatment of schizophrenia. Schizophrenia Bull. 45, S244-S245. doi: 10.1093/schbul/sbz019. 386

Brown, D. A. (2010). Muscarinic acetylcholine receptors (mAChRs) in the nervous system: some functions and mechanisms. J. Mol. Neurosci. 41, 340-346. doi: 10.1007/s12031-010-9377-2

Brown, D. A., and Adams, P. R. (1980). Muscarinic suppression of a novel voltagesensitive K+ current in a vertebrate neurone. Nature 283, 673-676. doi: 10.1038/ $283673 \mathrm{a} 0$ 
Bubser, M., Byun, N., Wood, M. R., and Jones, C. K. (2011). Muscarinic receptor pharmacology and circuitry for the modulation of cognition. Handb. Exp. Pharmacol. 208, 121-166. doi: 10.1007/978-3-642-23274-9_7

Buccafusco, J. J., Terry, A. V., Webster, S. J., Martin, D., Hohnadel, E. J., Bouchard, K. A., et al. (2008). The scopolamine-reversal paradigm in rats and monkeys: the importance of computer-assisted operant-conditioning memory tasks for screening drug candidates. Psychopharmacology 199, 481-494. doi: 10.1007/ s00213-007-0887-8

Carruthers, S. P., Gurvich, C. T., and Rossell, S. L. (2015). The muscarinic system, cognition and schizophrenia. Neurosci. Biobehav. Rev. 55, 393-402. doi: 10. 1016/j.neubiorev.2015.05.011

Caulfield, M. P., and Birdsall, N. J. (1998). International Union of Pharmacology. XVII. Classification of muscarinic acetylcholine receptors. Pharmacol. Rev. 50, 279-290.

Chen, N., Sugihara, H., and Sur, M. (2015). An acetylcholine-activated microcircuit drives temporal dynamics of cortical activity. Nat. Neurosci. 18, 892-902. doi: 10.1038/nn.4002

Cole, A., and Nicoll, R. (1983). Acetylcholine mediates a slow synaptic potential in hippocampal pyramidal cells. Science 221, 1299-1301. doi: 10.1126/science. 6612345

Condy, C., Wattiez, N., Rivaud-Péchoux, S., Tremblay, L., and Gaymard, B. (2007). Antisaccade deficit after inactivation of the principal sulcus in monkeys. Cereb. Cortex 17, 221-229. doi: 10.1093/cercor/bhj140

Constantinople, C. M., and Bruno, R. M. (2011). Effects and mechanisms of wakefulness on local cortical networks. Neuron 69, 1061-1068. doi: 10.1016/j. neuron.2011.02.040

Contreras, D., and Steriade, M. (1995). Cellular basis of EEG slow rhythms: a study of dynamic corticothalamic relationships. J. Neurosci. 15, 604-622. doi: 10.1523/jneurosci.15-01-00604.1995

Croxson, P. L., Kyriazis, D. A., and Baxter, M. G. (2011). Cholinergic modulation of a specific memory function of prefrontal cortex. Nat. Neurosci. 14, 1510-1512. doi: $10.1038 / \mathrm{nn} .2971$

Dagytë, G., Boer, J. A. D., and Trentani, A. (2011). The cholinergic system and depression. Behav. Brain Res. 221, 574-582. doi: 10.1016/j.bbr.2010.02.023

Davidson, M., and Marrocco, R. (2000). Local infusion of scopolamine into intraparietal cortex slows covert orienting in rhesus monkeys. J. Neurophysiol. $83,1536-1549$.

Davidson, M. C., Cutrell, E. B., and Marrocco, R. T. (1999). Scopolamine slows the orienting of attention in primates to cued visual targets. Psychopharmacology 142, 1-8. doi: 10.1007/s002130050855

Davies, R. H., Scholes, H. E., Virdi, S., and Broadley, K. J. (2001). Inhibition of field stimulation-induced contractions of rabbit vas deferens by muscarinic receptor agonists: selectivity of McN-A-343 for M1 receptors. J. Pharm. Pharmacol. 53, 487-496.

Dean, B., Bymaster, F., and Scarr, E. (2003). Muscarinic receptors in schizophrenia. Curr. Mol. Med. 3, 419-426. doi: 10.2174/1566524033479654

Dean, B., McLeod, M., Keriakous, D., McKenzie, J., and Scarr, E. (2002). Decreased muscarinicl receptors in the dorsolateral prefrontal cortex of subjects with schizophrenia. Mol. Psychiatr. 7, 1083-1091. doi: 10.1038/sj.mp. 4001199

Dean, B., and Scarr, E. (2016). COMT genotype is associated with differential expression of muscarinic M1 receptors in human cortex. Am. J. Med. Genet. B Neuropsychiatr. Genet. 171, 784-789. doi: 10.1002/ajmg.b.32440

Digby, G. J., Noetzel, M. J., Bubser, M., Utley, T. J., Walker, A. G., Byun, N. E., et al. (2012). Novel allosteric agonists of M1 muscarinic acetylcholine receptors induce brain region-specific responses that correspond with behavioral effects in animal models. J. Neurosci. 32, 8532-8544. doi: 10.1523/JNEUROSCI.033712.2012

Disney, A. A., and Aoki, C. (2008). Muscarinic acetylcholine receptors in macaque $\mathrm{V} 1$ are most frequently expressed by parvalbumin-immunoreactive neurons. J. Comp. Neurol. 507, 1748-1762. doi: 10.1002/cne.21616

Disney, A. A., Domakonda, K. V., and Aoki, C. (2006). Differential expression of muscarinic acetylcholine receptors across excitatory and inhibitory cells in visual cortical areas V1 and V2 of the macaque monkey. J. Comp. Neurol. 499, 49-63. doi: 10.1002/cne.21096

Disney, A. A., and Reynolds, J. H. (2014). Expression of m1-type muscarinic acetylcholine receptors by parvalbumin-immunoreactive neurons in the primary visual cortex: a comparative study of rat, guinea pig, ferret, macaque, and human. J. Comp. Neurol. 522, 986-1003. doi: 10.1002/cne. 23456

Dudar, J. D., and Szerb, J. C. (1969). The effect of topically applied atropine on resting and evoked cortical acetylcholine release. J. Physiol. 203, 741-762. doi: 10.1113/jphysiol.1969.sp008890

Dunnett, S. B., Wareham, A. T., and Torres, E. M. (1990). Cholinergic blockade in prefrontal cortex and hippocampus disrupts short-term memory in rats. Neuroreport 1, 61-64. doi: 10.1097/00001756-199009000-00017

Eckenstein, F., and Baughman, R. W. (1984). Two types of cholinergic innervation in cortex, one co-localized with vasoactive intestinal polypeptide. Nature 309, 153-155. doi: 10.1038/309153a0

Egorov, A. V., Hamam, B. N., Fransén, E., Hasselmo, M. E., and Alonso, A. A. (2002). Graded persistent activity in entorhinal cortex neurons. Nature 420, 173-178. doi: 10.1038/nature01171

Ellis, J. R., Ellis, K. A., Bartholomeusz, C. F., Harrison, B. J., Wesnes, K. A., Erskine, F. F., et al. (2006). Muscarinic and nicotinic receptors synergistically modulate working memory and attention in humans. Int. J. Neuropsychopharmacol. 9, 175-189. doi: 10.1017/S1461145705005407

Everling, S., and Fischer, B. (1998). The antisaccade: a review of basic research and clinical studies. Neuropsychologia 36, 885-899. doi: 10.1016/S0028-3932(98) 00020-7

Fibiger, H. C. (1991). Cholinergic mechanisms in learning, memory and dementia: a review of recent evidence. Trends Neurosci. 14, 220-223. doi: 10.1016/01662236(91)90117-D

Flynn, D. D., Ferrari-DiLeo, G., Levey, A. I., and Mash, D. C. (1995). Differential alterations in muscarinic receptor subtypes in Alzheimer's disease: implications for cholinergic-based therapies. Life Sci. 56, 869-876. doi: 10.1016/00243205(95)00022-x

Funahashi, S., Bruce, C. J., and Goldman-Rakic, P. S. (1989). Mnemonic coding of visual space in the monkey's dorsolateral prefrontal cortex. J. Neurophysiol. 61, 331-349. doi: 10.1152/jn.1989.61.2.331

Fuster, J. M. (1992). Prefrontal neurons and the cognitive foundation of motor action. Adv. Neurol. 57, 351-360.

Fuster, J. M. (1993). Frontal lobes. Curr. Opin. Neurobiol. 3, 160-165. doi: 10.1016/ 0959-4388(93)90204-c

Fuster, J. M., and Alexander, G. E. (1971). Neuron activity related to short-term memory. Science 173, 652-654. doi: 10.1126/science.173.3997.652

Galvin, V. C., Arnsten, A. F., and Wang, M. (2018). Evolution in neuromodulation-the differential roles of acetylcholine in higher order association vs. Primary visual cortices. Front. Neural Circ. 12:67. doi: $10.3389 /$ fncir.2018.00067

Galvin, V. C., Arnsten, A. F. T., and Wang, M. (2020a). Behavioral pharmacology of the cholinergic system. Curr. Top. Behav. Neurosci. 45, 89-99. doi: 10.1007/ 7854_2020_142

Galvin, V. C., Yang, S. T., Paspalas, C. D., Yang, Y., Jin, L. E., Datta, D., et al. (2020b). Muscarinic M1 receptors modulate working memory performance and activity via KCNQ potassium channels in the primate prefrontal cortex. Neuron 106, 649-661e4. doi: 10.1016/j.neuron.2020.02.030

Giachetti, A., Giraldo, E., Ladinsky, H., and Montagna, E. (1986). Binding and functional profiles of the selective M1 muscarinic receptor antagonists trihexyphenidyl and dicyclomine. Brit. J. Pharmacol. 89, 83-90. doi: 10.1111/ j.1476-5381.1986.tb11123.x

Gil, Z., Connors, B. W., and Amitai, Y. (1997). Differential regulation of neocortical synapses by neuromodulators and activity. Neuron 19, 679-686. doi: 10.1016/ s0896-6273(00)80380-3

Gillin, J. C., Sutton, L., Ruiz, C., Golshan, S., Hirsch, S., Warmann, C., et al. (1991). Dose dependent inhibition of REM sleep in normal volunteers by biperiden, a muscarinic antagonist. Biol. Psychiat. 30, 151-156. doi: 10.1016/0006-3223(91) 90169-m

Goldman-Rakic, P., and Schwartz, M. (1982). Interdigitation of contralateral and ipsilateral columnar projections to frontal association cortex in primates. Science 216, 755-757. doi: 10.1126/science.6177037

Goldman-Rakic, P. S. (1995). Cellular basis of working memory. Neuron 14, 477-485. doi: 10.1016/0896-6273(95)90304-6

Green, A., Ellis, K. A., Ellis, J., Bartholomeusz, C. F., Ilic, S., Croft, R. J., et al. (2005). Muscarinic and nicotinic receptor modulation of object and spatial n-back working memory in humans. Pharmacol. Biochem. Behav. 81, 575-584. doi: $10.1016 /$ j.pbb.2005.04.010 
Gulledge, A. T., and Stuart, G. J. (2005). Cholinergic inhibition of neocortical pyramidal neurons. J. Neurosci. 25, 10308-10320. doi: 10.1523/JNEUROSCI. 2697-05.2005

Hagenston, A. M., Fitzpatrick, J. S., and Yeckel, M. F. (2008). MGluR-mediated calcium waves that invade the soma regulate firing in layer $\mathrm{V}$ medial prefrontal cortical pyramidal neurons. Cereb. Cortex 18, 407-423. doi: 10.1093/cercor/ bhm 075

Hampel, H., Mesulam, M.-M., Cuello, A. C., Khachaturian, A. S., Vergallo, A., Farlow, M. R., et al. (2019). Revisiting the cholinergic hypothesis in Alzheimer's disease: emerging evidence from translational and clinical research. J. Prev. Alzheimers Dis. 6, 2-15. doi: 10.14283/jpad.2018.43

Hampel, H., Mesulam, M.-M., Cuello, C. A., Farlow, M. R., Giacobini, E., Grossberg, G. T., et al. (2018). The cholinergic system in the pathophysiology and treatment of Alzheimer's disease. Brain 141, 1917-1933. doi: 10.1093/brain/ awy 132

Hasselmo, M. E., and Bower, J. M. (1992). Cholinergic suppression specific to intrinsic not afferent fiber synapses in rat piriform (olfactory) cortex. J. Neurophysiol. 67, 1222-1229. doi: 10.1152/jn.1992.67.5.1222

Herrero, J. L., Roberts, M. J., Delicato, L. S., Gieselmann, M. A., Dayan, P., and Thiele, A. (2008). Acetylcholine contributes through muscarinic receptors to attentional modulation in V1. Nature 454, 1110-1114. doi: 10.1038/ nature 07141

Hicks, T. P. (1984). The history and development of microiontophoresis in experimental neurobiology. Prog. Neurobiol. 22, 185-240.

Hikosaka, O., and Wurtz, R. H. (1983). Visual and oculomotor functions of monkey substantia nigra pars reticulata. III. Memory-contingent visual and saccade responses. J. Neurophysiol. 49, 1268-1284. doi: 10.1152/jn.1983.49.5. 1268

Hohagen, F., Riemann, D., Spiegel, R., Holzhauer, M., and Berger, M. (1993). Influence of the cholinergic agonist SDZ 210-086 on sleep in healthy subjects. Neuropsychopharmacol 9, 225-232. doi: 10.1038/npp.1993.58

Hsieh, C. Y., Cruikshank, S. J., and Metherate, R. (2000). Differential modulation of auditory thalamocortical and intracortical synaptic transmission by cholinergic agonist. Brain Res. 880, 51-64. doi: 10.1016/s0006-8993(00)02766-9

Jentsch, T. J. (2000). Neuronal KCNQ potassium channels: physiology and role in disease. Nat. Rev. Neurosci. 1, 21-30. doi: 10.1038/35036198

Jiang, S., Li, Y., Zhang, C., Zhao, Y., Bu, G., Xu, H., et al. (2014). M1 muscarinic acetylcholine receptor in Alzheimer's disease. Neurosci. Bull. 30, 295-307. doi: 10.1007/s12264-013-1406-z

Johnston, K., Levin, H. M., Koval, M. J., and Everling, S. (2007). Top-down controlsignal dynamics in anterior cingulate and prefrontal cortex neurons following task switching. Neuron 53, 453-462. doi: 10.1016/j.neuron.2006.12.023

Jones, B. E. (2008). Modulation of cortical activation and behavioral arousal by cholinergic and orexinergic systems. Ann. N. Y. Acad. Sci. 1129, 26-34. doi: 10.1196/annals. 1417.026

Jones, B. E. (2020). Arousal and sleep circuits. Neuropsychopharmacology 45, 6-20. doi: 10.1038/s41386-019-0444-2

Jones, C. K., Byun, N., and Bubser, M. (2012). Muscarinic and nicotinic acetylcholine receptor agonists and allosteric modulators for the treatment of schizophrenia. Neuropsychopharmacology 37, 16-42. doi: 10.1038/npp.2011. 199

Jones, C. K., and Shannon, H. E. (2000). Muscarinic cholinergic modulation of prepulse inhibition of the acoustic startle reflex. J. Pharmacol. Exp. Ther. 294, $1017-1023$.

Kim, E.-J., and Jeong, D.-U. (1999). Transdermal scopolamine alters phasic REM activity in normal young adults. Sleep 22, 515-520. doi: 10.1093/sleep/22. 4.515

Kimura, F., and Baughman, R. W. (1997). Distinct muscarinic receptor subtypes suppress excitatory and inhibitory synaptic responses in cortical neurons. J. Neurophysiol. 77, 709-716. doi: 10.1152/jn.1997.77.2.709

Klinkenberg, I., and Blokland, A. (2010). The validity of scopolamine as a pharmacological model for cognitive impairment: a review of animal behavioral studies. Neurosci. Biobehav. Rev. 34, 1307-1350. doi: 10.1016/j.neubiorev.2010. 04.001

Koval, M. J., Lomber, S. G., and Everling, S. (2011). Prefrontal cortex deactivation in macaques alters activity in the superior colliculus and impairs voluntary control of saccades. J. Neurosci. 31, 8659-8668. doi: 10.1523/JNEUROSCI.125811.2011
Krnjević, K., Reiffenstein, R. J., and Ropert, N. (1981). Disinhibitory action of acetylcholine in the rat's hippocampus: extracellular observations. Neuroscience 6, 2465-2474. doi: 10.1016/0306-4522(81)90092-0

Lebois, E. P., Bridges, T. M., Lewis, L. M., Dawson, E. S., Kane, A. S., Xiang, Z., et al. (2010). Discovery and characterization of novel subtype-selective allosteric agonists for the investigation of $\mathrm{M}(1)$ receptor function in the central nervous system. ACS Chem. Neurosci. 1, 104-121. doi: 10.1021/cn900003h

Lee, S.-H., and Dan, Y. (2012). Neuromodulation of brain states. Neuron 76, 209-222. doi: 10.1016/j.neuron.2012.09.012

Levey, A. I. (1996). Muscarinic acetylcholine receptor expression in memory circuits: implications for treatment of Alzheimer?disease. Proc. Natl. Acad. Sci. U.S.A. 93, 13541-13546. doi: 10.1073/pnas.93.24.13541

Levey, A. I., Edmunds, S. M., Heilman, C. J., Desmond, T. J., and Frey, K. A. (1994). Localization of muscarinic $\mathrm{M} 3$ receptor protein and $\mathrm{M} 3$ receptor binding in rat brain. Neuroscience 63, 207-221. doi: 10.1016/0306-4522(94)90017-5

Levey, A. I., Kitt, C. A., Simonds, W. F., Price, D. L., and Brann, M. R. (1991). Identification and localization of muscarinic acetylcholine receptor proteins in brain with subtype-specific antibodies. J. Neurosci. 11, 3218-3226.

Lewis, D. A. (1991). Distribution of choline acetyltransferase-immunoreactive axons in monkey frontal cortex. Neuroscience 40, 363-374. doi: 10.1016/03064522(91)90126-9

Lewis, L. D., Weiner, V. S., Mukamel, E. A., Donoghue, J. A., Eskandar, E. N., Madsen, J. R., et al. (2012). Rapid fragmentation of neuronal networks at the onset of propofol-induced unconsciousness. Proc. Natl. Acad. Sci. U.S.A. 109, E3377-E3386. doi: 10.1073/pnas.1210907109

Lidow, M. S., Gallager, D. W., Rakic, P., and Goldman-Rakic, P. S. (1989). Regional differences in the distribution of muscarinic cholinergic receptors in the macaque cerebral cortex. J. Comp. Neurol. 289, 247-259. doi: 10.1002/cne. 902890206

Liu, R., Crawford, J., Callahan, P. M., Terry, A. V., Constantinidis, C., and Blake, D. T. (2017). Intermittent stimulation of the nucleus basalis of meynert improves working memory in adult monkeys. Curr. Biol. 27, 2640-2646.e4. doi: 10.1016/j.cub.2017.07.021

Lv, X., Dickerson, J. W., Rook, J. M., Lindsley, C. W., Conn, P. J., and Xiang, Z. (2017). M1 muscarinic activation induces long-lasting increase in intrinsic excitability of striatal projection neurons. Neuropharmacology 118, 209-222. doi: 10.1016/j.neuropharm.2017.03.017

Maeda, S., Qu, Q., Robertson, M. J., Skiniotis, G., and Kobilka, B. K. (2019). Structures of the M1 and M2 muscarinic acetylcholine receptor/G-protein complexes. Science 364, 552-557. doi: 10.1126/science.aaw5188

Major, A. J., Vijayraghavan, S., and Everling, S. (2015). Muscarinic attenuation of mnemonic rule representation in macaque dorsolateral prefrontal cortex during a pro- and anti-saccade task. J. Neurosci. 35, 16064-16076. doi: 10.1523/ jneurosci.2454-15.2015

Major, A. J., Vijayraghavan, S., and Everling, S. (2018). Cholinergic overstimulation attenuates rule selectivity in macaque prefrontal cortex. J. Neurosci. 38, 11371150. doi: $10.1523 /$ jneurosci.3198-17.2017

Marrion, N. V. (1997). Control of M-current. Annu. Rev. Physiol. 59, 483-504. doi: 10.1146/annurev.physiol.59.1.483

Marucci, G., Buccioni, M., Ben, D. D., Lambertucci, C., Volpini, R., and Amenta, F. (2020). Efficacy of acetylcholinesterase inhibitors in Alzheimer's disease. Neuropharmacology doi: 10.1016/j.neuropharm.2020.108352 [Epub ahead of print],

Mash, D., Flynn, D., and Potter, L. (1985). Loss of M2 muscarine receptors in the cerebral cortex in Alzheimer's disease and experimental cholinergic denervation. Science 228, 1115-1117. doi: 10.1126/science.3992249

Mash, D. C., and Potter, L. T. (1986). Autoradiographic localization of M1 and M2 muscarine receptors in the rat brain. Neuroscience 19, 551-564. doi: 10.1016/ 0306-4522(86)90280-0

McCormick, D. A. (1989). Cholinergic and noradrenergic modulation of thalamocortical processing. Trends Neurosci. 12, 215-221. doi: 10.1016/01662236(89)90125-2

McCormick, D. A. (1993). Chapter 36: actions of acetylcholine in the cerebral cortex and thalamus and implications for function. Prog. Brain Res. 98, 303-308. doi: 10.1016/s0079-6123(08)62412-7

McCormick, D. A., and Prince, D. A. (1986). Mechanisms of action of acetylcholine in the guinea-pig cerebral cortex in vitro. J. Physiol. 375, 169-194. doi: 10.1113/ jphysiol.1986.sp016112 
McCormick, D. A., Wang, Z., and Huguenard, J. (1993). Neurotransmitter control of neocortical neuronal activity and excitability. Cereb. Cortex 3, 387-398.

Medalla, M., and Barbas, H. (2012). The anterior cingulate cortex may enhance inhibition of lateral prefrontal cortex via $\mathrm{m} 2$ cholinergic receptors at dual synaptic sites. J. Neurosci. 32, 15611-15625. doi: 10.1523/jneurosci.2339-12. 2012

Mesulam, M.-M., Mufson, E. J., Wainer, B. H., and Levey, A. I. (1983). Central cholinergic pathways in the rat: an overview based on an alternative nomenclature (Ch1-Ch6). Neuroscience 10, 1185-1201. doi: 10.1016/03064522(83)90108-2

Metherate, R., Cox, C., and Ashe, J. (1992). Cellular bases of neocortical activation: modulation of neural oscillations by the nucleus basalis and endogenous acetylcholine. J. Neurosci. 12, 4701-4711. doi: 10.1523/jneurosci.12-12-04701. 1992

Miller, E., and Cohen, J. (2001). An integrative theory of prefrontal cortex function. Annu. Rev. Neurosci. 24, 167-202. doi: 10.1146/annurev.neuro.24.1.167

Miller, E., and Desimone, R. (1992). Scopolamine affects short-term memory but not inferior temporal neurons. Neuroreport 4, 81-84.

Mitchelson, F. J. (2012). The pharmacology of McN-A-343. Pharmacol. Ther. 135, 216-245. doi: 10.1016/j.pharmthera.2012.05.008

Moruzzi, G., and Magoun, H. W. (1949). Brain stem reticular formation and activation of the EEG. Electroencephalogr. Clin. Neurophysiol. 1, 455-473. doi: 10.1016/0013-4694(49)90219-9

Mrzljak, L., Levey, A. I, Belcher, S., and Goldman-Rakic, P. S. (1998). Localization of the $\mathrm{m} 2$ muscarinic acetylcholine receptor protein and mRNA in cortical neurons of the normal and cholinergically deafferented rhesus monkey. J. Comp. Neurol. 390, 112-132.

Mrzljak, L., Levey, A. I., and Goldman-Rakic, P. S. (1993). Association of $\mathrm{m} 1$ and $\mathrm{m} 2$ muscarinic receptor proteins with asymmetric synapses in the primate cerebral cortex: morphological evidence for cholinergic modulation of excitatory neurotransmission. Proc. Natl. Acad. Sci. U.S.A. 90, 5194-5198. doi: 10.1073/pnas.90.11.5194

Mrzljak, L., Levey, A. I., and Rakic, P. (1996). Selective expression of m2 muscarinic receptor in the parvocellular channel of the primate visual cortex. Proc. Natl. Acad. Sci. U.S.A. 93, 7337-7340. doi: 10.1073/pnas.93.14.7337

Mrzljak, L., Pappy, M., Leranth, C., and Goldman-Rakic, P. (1995). Cholinergic synaptic circuitry in the macaque prefrontal cortex. J. Comp. Neurol. 357, 603-617. doi: 10.1002/cne.903570409

Murakoshi, T. (1995). Cholinergic modulation of synaptic transmission in the rat visual cortex in vitro. Vis. Res. 35, 25-35. doi: 10.1016/0042-6989(94)e0056-q

Muzur, A., Pace-Schott, E. F., and Hobson, J. A. (2002). The prefrontal cortex in sleep. Trends Cogn. Sci. 6, 475-481. doi: 10.1016/s1364-6613(02)01992-7

Navarria, A., Wohleb, E. S., Voleti, B., Ota, K. T., Dutheil, S., Lepack, A. E., et al. (2015). Rapid antidepressant actions of scopolamine: Role of medial prefrontal cortex and M1-subtype muscarinic acetylcholine receptors. Neurobiol. Dis. 82, 254-261. doi: 10.1016/j.nbd.2015.06.012

Niwa, Y., Kanda, G. N., Yamada, R. G., Shi, S., Sunagawa, G. A., Ukai-Tadenuma, M., et al. (2018). Muscarinic acetylcholine receptors Chrm1 and Chrm3 are essential for REM sleep. Cell Rep. 24, 2231-2247.e7. doi: 10.1016/j.celrep.2018. 07.082

Noufi, P., Khoury, R., Jeyakumar, S., and Grossberg, G. T. (2019). Use of cholinesterase inhibitors in non-Alzheimer's dementias. Drug Aging 36, 719731. doi: 10.1007/s40266-019-00685-6

Ott, T., and Nieder, A. (2019). Dopamine and cognitive control in prefrontal cortex. Trends Cogn. Sci. 23, 213-234. doi: 10.1016/j.tics.2018.12.006

Parikh, V., Kozak, R., Martinez, V., and Sarter, M. (2007). Prefrontal acetylcholine release controls cue detection on multiple timescales. Neuron 56, 141-154. doi: 10.1016/j.neuron.2007.08.025

Parikh, V., Pomerleau, F., Huettl, P., Gerhardt, G. A., Sarter, M., and Bruno, J. P. (2004). Rapid assessment of in vivo cholinergic transmission by amperometric detection of changes in extracellular choline levels. Eur. J. Neurosci. 20, 15451554. doi: 10.1111/j.1460-9568.2004.03614.x

Penetar, D. M., and McDonough, J. H. (1983). Effects of cholinergic drugs on delayed match-to-sample performance of rhesus monkeys. Pharmacol. Biochem. Behav. 19, 963-967. doi: 10.1016/0091-3057(83)90399-4

Picciotto, M. R., Higley, M. J., and Mineur, Y. S. (2012). Acetylcholine as a neuromodulator: cholinergic signaling shapes nervous system function and behavior. Neuron 76, 116-129. doi: 10.1016/j.neuron.2012.08.036
Plakke, B., Ng, C.-W., and Poremba, A. (2008). Scopolamine impairs auditory delayed matching-to-sample performance in monkeys. Neurosci. Lett. 438, 126-130. doi: 10.1016/j.neulet.2008.04.015

Popiolek, M., Nguyen, D. P., Reinhart, V., Edgerton, J. R., Harms, J., Lotarski, S. M., et al. (2016). Inositol phosphate accumulation in vivo provides a measure of muscarinic M1 receptor activation. Biochemistry 55, 7073-7085. doi: 10.1021/ acs.biochem.6b00688

Pucak, M., Levitt, J., Lund, J., and Lewis, D. (1996). Patterns of intrinsic and associational circuitry in monkey prefrontal cortex. J. Comp. Neurol. 376, 614-630. doi: 10.1002/(SICI)1096-9861(19961223)376

Richardson, R., and DeLong, M. (1986). Nucleus basalis of Meynert neuronal activity during a delayed response task in monkey. Brain Res. 399, 364-368. doi: 10.1016/0006-8993(86)91529-5

Richardson, R. T., and DeLong, M. R. (1991). The Basal forebrain. Anat. Funct. Adv. Exp. Med. Biol. 295, 233-252. doi: 10.1007/978-1-4757-0145-6_12

Robbins, T., and Arnsten, A. (2009). The neuropsychopharmacology of frontoexecutive function: monoaminergic modulation. Annu. Rev. Neurosci. 32, 267-287. doi: 10.1146/annurev.neuro.051508.135535

Ruivo, L. M. T.-G., Baker, K. L., Conway, M. W., Kinsley, P. J., Gilmour, G., Phillips, K. G., et al. (2017). Coordinated acetylcholine release in prefrontal cortex and hippocampus is associated with arousal and reward on distinct timescales. Cell Rep. 18, 905-917. doi: 10.1016/j.celrep.2016.12.085

Rupniak, N., Samson, N., Tye, S., Field, M., and Iversen, S. (1991). Evidence against a specific effect of cholinergic drugs on spatial memory in primates. Behav. Brain Res. 43, 1-6. doi: 10.1016/S0166-4328(05)80047-6

Rusted, J. M., Eaton-Williams, P., and Warburton, D. M. (1991). A comparison of the effects of scopolamine and diazepam on working memory. Psychopharmacology 105, 442-445. doi: 10.1007/bf02244443

Rusted, J. M., and Warburton, D. M. (1988). The effects of scopolamine on working memory in healthy young volunteers. Psychopharmacology 96, 145-152. doi: $10.1007 / \mathrm{bf00177553}$

Saar, D., Grossman, Y., and Barkai, E. (2001). Long-lasting cholinergic modulation underlies rule learning in rats. J. Neurosci. 21, 1385-1392. doi: 10.1523/ jneurosci.21-04-01385.2001

Sanchez-Vives, M. V., Massimini, M., and Mattia, M. (2017). Shaping the default activity pattern of the cortical network. Neuron 94, 993-1001. doi: 10.1016/j. neuron.2017.05.015

Sanchez-Vives, M. V., and McCormick, D. A. (2000). Cellular and network mechanisms of rhythmic recurrent activity in neocortex. Nat. Neurosci. 3, 1027-1034. doi: 10.1038/79848

Sarter, M., and Bruno, J. P. (1997). Cognitive functions of cortical acetylcholine: toward a unifying hypothesis. Brain Res. Rev. 23, 28-46. doi: 10.1016/s01650173(96)00009-4

Sarter, M., and Bruno, J. P. (1998). Cortical acetylcholine, reality distortion, schizophrenia, and lewy body dementia: too much or too little cortical acetylcholine? Brain Cogn. 38, 297-316. doi: 10.1006/brcg.1998.1035

Scarr, E., Cowie, T. F., Kanellakis, S., Sundram, S., Pantelis, C., and Dean, B. (2009). Decreased cortical muscarinic receptors define a subgroup of subjects with schizophrenia. Mol. Psychiatry 14, 1017-1023. doi: 10.1038/mp. 2008.28

Schwartz, M. L., and Goldman-Rakic, P. S. (1984). Callosal and intrahemispheric connectivity of the prefrontal association cortex in rhesus monkey: relation between intraparietal and principal sulcal cortex. J. Comp. Neurol. 226, 403-420. doi: 10.1002/cne.902260309

Shekhar, A., Potter, W. Z., Lightfoot, J., Lienemann, J., Dub, S., Mallinckrodt, C., et al. (2008). Selective muscarinic receptor agonist xanomeline as a novel treatment approach for schizophrenia. Am. J. Psychiatr. 165, 1033-1039. doi: 10.1176/appi.ajp.2008.06091591

Shirey, J. K., Brady, A. E., Jones, P. J., Davis, A. A., Bridges, T. M., Kennedy, J. P., et al. (2009). A selective allosteric potentiator of the M1 muscarinic acetylcholine receptor increases activity of medial prefrontal cortical neurons and restores impairments in reversal learning. J. Neurosci. 29, 14271-14286. doi: 10.1523/JNEUROSCI.3930-09.2009

Sitaram, N., Wyatt, R., Dawson, S., and Gillin, J. (1976). REM sleep induction by physostigmine infusion during sleep. Science 191, 1281-1283. doi: 10.1126/ science. 176724

Skoblenick, K., and Everling, S. (2012). NMDA antagonist ketamine reduces task selectivity in macaque dorsolateral prefrontal neurons and impairs performance 
of randomly interleaved prosaccades and antisaccades. J. Neurosci. 32, 1201812027. doi: 10.1523/JNEUROSCI.1510-12.2012

Smiley, J. F., Morrell, F., and Mesulam, M. M. (1997). Cholinergic synapses in human cerebral cortex: an ultrastructural study in serial sections. Exp. Neurol. 144, 361-368. doi: 10.1006/exnr.1997.6413

Spinelli, S., Ballard, T., Feldon, J., Higgins, G., and Pryce, C. (2006). Enhancing effects of nicotine and impairing effects of scopolamine on distinct aspects of performance in computerized attention and working memory tasks in marmoset monkeys. Neuropharmacology 51, 238-250. doi: 10.1016/j. neuropharm.2006.03.012

Steriade, M. (2004). Acetylcholine systems and rhythmic activities during the waking-sleep cycle. Prog. Brain Res. 145, 179-196. doi: 10.1016/s0079-6123(03) 45013-9

Steriade, M., Timofeev, I., and Grenier, F. (2001). Natural waking and sleep states: a view from inside neocortical neurons. J. Neurophysiol. 85, 1969-1985. doi: 10.1152/jn.2001.85.5.1969

Suh, B., and Hille, B. (2007). Regulation of KCNQ channels by manipulation of phosphoinositides. J. Physiol. 582, 911-916. doi: 10.1113/jphysiol.2007.132647

Suh, B.-C., and Hille, B. (2002). Recovery from muscarinic modulation of M current channels requires Phosphatidylinositol 4,5-Bisphosphate synthesis. Neuron 35, 507-520. doi: 10.1016/s0896-6273(02)00790-0

Suh, B.-C., and Hille, B. (2005). Regulation of ion channels by phosphatidylinositol 4,5-bisphosphate. Curr. Opin. Neurobiol. 15, 370-378. doi: 10.1016/j.conb.2005. 05.005

Suh, B.-C., Inoue, T., Meyer, T., and Hille, B. (2006). Rapid chemically induced changes of PtdIns(4,5)P2 Gate KCNQ ion channels. Science 314, 1454-1457. doi: $10.1126 /$ science. 1131163

Sun, H., and Neugebauer, V. (2011). mGluR1, but not mGluR5, activates feedforward inhibition in the medial prefrontal cortex to impair decision making. J. Neurophysiol. 106, 960-973. doi: 10.1152/jn.00762.2010

Sun, Y., Yang, Y., Galvin, V. C., Yang, S., Arnsten, A. F., and Wang, M. (2017). Nicotinic $\alpha 4 \beta 2$ cholinergic receptor influences on dorsolateral prefrontal cortical neuronal firing during a working memory task. J. Neurosci. 37, 53665377. doi: 10.1523/JNEUROSCI.0364-17.2017

Thiele, A. (2013). Muscarinic signaling in the brain. Annu. Rev. Neurosci. 36, 271-294. doi: 10.1146/annurev-neuro-062012-170433

Ukai, M., Okuda, A., and Mamiya, T. (2004). Effects of anticholinergic drugs selective for muscarinic receptor subtypes on prepulse inhibition in mice. Eur. J. Pharmacol. 492, 183-187. doi: 10.1016/j.ejphar.2004.03.066

Uslaner, J. M., Eddins, D., Puri, V., Cannon, C. E., Sutcliffe, J., Chew, C. S., et al. (2013). The muscarinic M1 receptor positive allosteric modulator PQCA improves cognitive measures in rat, cynomolgus macaque, and rhesus macaque. Psychopharmacology 225, 21-30. doi: 10.1007/s00213-012-2788-8

Velazquez-Moctezuma, J., Shalauta, M. D., Gillin, J. C., and Shiromani, P. J. (1990). Differential effects of cholinergic antagonists on REM sleep components. Psychopharmacol. Bull. 26, 349-353.

Venkatesan, S., Jeoung, H.-S., Chen, T., Power, S. K., Liu, Y., and Lambe, E. K. (2020). Behavioral pharmacology of the cholinergic system. Curr. Top. Behav. Neurosci. 45, 47-69. doi: 10.1007/7854_2020_138

Vijayraghavan, S., Major, A., and Everling, S. (2018). Muscarinic M1 receptor overstimulation disrupts working memory activity for rules in primate prefrontal cortex. Neuron 98, 1256-1268.e4. doi: 10.1016/j.neuron.2018.05.027

Vijayraghavan, S., Major, A. J., and Everling, S. (2016). Dopamine D1 and D2 receptors make dissociable contributions to dorsolateral prefrontal cortical regulation of rule-guided oculomotor behavior. Cell Rep. 16, 805-816. doi: 10.1016/j.celrep.2016.06.031
Vijayraghavan, S., Major, A. J., and Everling, S. (2017). Neuromodulation of prefrontal cortex in non-human primates by dopaminergic receptors during rule-guided flexible behavior and cognitive control. Front. Neural Circ. 11:91. doi: $10.3389 /$ fncir.2017.00091

Voytko, M., Olton, D., Richardson, R., Gorman, L., Tobin, J., and Price, D. (1994). Basal forebrain lesions in monkeys disrupt attention but not learning and memory [published erratum appears in J Neurosci 1995 Mar;15(3): following table of contents]. J. Neurosci. 14, 167-186. doi: 10.1523/jneurosci.14-01-00167. 1994

Wallace, T. L., and Bertrand, D. (2013). Importance of the nicotinic acetylcholine receptor system in the prefrontal cortex. Biochem. Pharmacol. 85, 1713-1720. doi: 10.1016/j.bcp.2013.04.001

Wang, M., Gamo, N. J., Yang, Y., Jin, L. E., Wang, X.-J., Laubach, M., et al. (2011). Neuronal basis of age-related working memory decline. Nature 476, 210. doi: $10.1038 /$ nature 10243

Wang, M., Vijayraghavan, S., and Goldman-Rakic, P. S. (2004). Selective D2 receptor actions on the functional circuitry of working memory. Science 303, 853-856. doi: 10.1126/science. 1091162

Wang, X.-J. (2001). Synaptic reverberation underlying mnemonic persistent activity. Trends Neurosci. 24, 455-463. doi: 10.1016/s0166-2236(00) 01868-3

Yang, Y., Paspalas, C. D., Jin, L. E., Picciotto, M. R., Arnsten, A. F. T., and Wang, M. (2013). Nicotinic $\alpha 7$ receptors enhance NMDA cognitive circuits in dorsolateral prefrontal cortex. Proc. Natl. Acad. Sci. U.S.A. 110, 12078-12083. doi: 10.1073/pnas.1307849110

Yeomans, J. (1995). Role of tegmental cholinergic neurons in dopaminergic activation, antimuscarinic psychosis and schizophrenia. Neuropsychopharmacology 12, 3-16.

Yi, F., Ball, J., Stoll, K. E., Satpute, V. C., Mitchell, S. M., Pauli, J. L., et al. (2014). Direct excitation of parvalbumin-positive interneurons by M1 muscarinic acetylcholine receptors: roles in cellular excitability, inhibitory transmission and cognition. J. Physiol. 592, 3463-3494. doi: 10.1113/jphysiol.2014. 275453

Young, M. B., and Thomas, S. A. (2014). M1-muscarinic receptors promote fear memory consolidation via phospholipase C and the M-current. J. Neurosci. 34, 1570-1578. doi: 10.1523/JNEUROSCI.1040-13.2014

Zhang, W., Basile, A. S., Gomeza, J., Volpicelli, L. A., Levey, A. I., and Wess, J. (2002). Characterization of central inhibitory muscarinic autoreceptors by the use of muscarinic acetylcholine receptor knock-out mice. J. Neurosci. 22, 1709-1717. doi: 10.1523/jneurosci.22-05-01709.2002

Zhou, X., Qi, X.-L. L., Douglas, K., Palaninathan, K., Kang, H. S., Buccafusco, J. J., et al. (2011). Cholinergic modulation of working memory activity in primate prefrontal cortex. J. Neurophysiol. 106, 2180-2188. doi: 10.1152/jn.00148. 2011

Conflict of Interest: The authors declare that the research was conducted in the absence of any commercial or financial relationships that could be construed as a potential conflict of interest.

Copyright (c) 2021 Vijayraghavan and Everling. This is an open-access article distributed under the terms of the Creative Commons Attribution License (CC BY). The use, distribution or reproduction in other forums is permitted, provided the original author(s) and the copyright owner(s) are credited and that the original publication in this journal is cited, in accordance with accepted academic practice. No use, distribution or reproduction is permitted which does not comply with these terms. 